\title{
Behavioral and associative effects of differential outcomes in discrimination learning
}

\author{
PETER J. URCUIOLI \\ Purdue University, West Lafayette, Indiana
}

\begin{abstract}
The role of the reinforcer in instrumental discriminations has often been viewed as that of facilitating associative learning between a reinforced response and the discriminative stimulus that occasions it. The differential-outcome paradigm introduced by Trapold (1970), however, has provided compelling evidence that reinforcers are also part of what is learned in discrimination tasks. Specifically, when the availability of different reinforcing outcomes is signaled by different discriminative stimuli, the conditioned anticipation of those outcomes can provide another source of stimulus control over responding. This article reviews how such control develops and how it can be revealed, its impact on behavior, and different possible mechanisms that could mediate the behavioral effects. The main conclusion is that differential-outcome effects are almost entirely explicable in terms of the cue properties of outcome expectancies-namely, that conditioned expectancies acquire discriminative control just like any other discriminative or conditional stimulus in instrumental learning.
\end{abstract}

This article reviews and critiques the substantial literature on how discrimination learning and performance are affected when response-contingent outcomes differ across reinforced responses. Traditionally, the scheduling of different reinforcers for different responses has been atypical in laboratory studies of discrimination learning, despite that fact that in real-world settings, reinforcers vary considerably from one behavior to another. The contingencies most often studied in the laboratory involve a common reinforcer for all responses, an arrangement that in large part reflects historical ideas about the role of reinforcers in instrumental learning. Besides, discriminative responding often develops quite readily under commonreinforcer conditions, a finding that itself tends to encourage the notion that the important relations in discrimination learning are those between the discriminative stimuli and the responses reinforced in their presence. Without denying the basic processes of how behavior comes under stimulus control, there is more to discrimination learning than just a connection between discriminative stimuli and reinforced responses. This point has been made most forcefully by studies in which discriminative responding yields different reinforcers - that is, differential outcomes.

The differential-outcome paradigm has had a profound impact on our understanding of the behavioral and associative processes involved when subjects learn to re-

Preparation of this article was made possible by NIMH Grant MH 66195 to P.J.U. The author's cited research was supported by National Science Foundation Grants 86-06926 and IBN 94-19929 and by NIMH Grant 45979. Correspondence concerning this article should be addressed to P. J. Urcuioli, Department of Psychological Sciences, Purdue University, 703 Third Street, West Lafayette, IN 47907-2081 (e-mail: uche@psych.purdue.edu). spond differentially to different environmental events. It has provided a wealth of useful information about the speed with which discriminations are learned, the ability of learned performances to survive delays between the discriminative stimuli and the opportunity to respond, transfer of performance across disparate stimuli, and the associative relations to which subjects are sensitive and that underlie these behavioral effects. Differentialoutcome data have contributed substantially to theoretical analyses of discrimination learning, in particular, and instrumental learning, in general (e.g., Colwill, 1994; Colwill \& Rescorla, 1986; Urcuioli \& DeMarse, 1996), and to the understanding of diverse issues, such as the nature of working memory (e.g., Honig \& Dodd, 1986; Overmier, Savage, \& Sweeney, 1999; Urcuioli \& Zentall, 1992), the origins of equivalence classes (e.g., Astley \& Wasserman, 1999; de Rose, McIlvane, Dube, Galpin, \& Stoddard, 1988; Edwards, Jagielo, Zentall, \& Hogan, 1982), the neural bases of associative learning (e.g., Blundell, Hall, \& Killcross, 2001; Savage, 2001; Savage \& Parsons, 1997; see also Donahoe \& Burgos, 2000), and behavioral remediation (e.g., Estévez, Fuentes, Overmier, \& González, 2003; Hochhalter \& Joseph, 2001; Malanga \& Poling, 1992; Overmier et al., 1999).

Given these extensive empirical and theoretical contributions, I cannot discuss each and every one in a way that does them justice. Nor will I attempt a thorough analysis of each topic I do address. The main purpose of my article is to underscore what I see as the main message arising from the study of differential outcomesnamely, that the reinforcer itself is part of what is learned. How reinforcers enter into the learning matrix remains a topic of debate. My position will be that when a response-specific reinforcer is predictable prior to responding, the subject's ability to anticipate that sched- 
uled reinforcer can, and does, guide the subject's behavior, just as does any other discriminative stimulus. In other words, differential outcomes introduce another potential cue into discrimination tasks, and that cue has behavioral effects that can be understood in terms of standard principles of stimulus control (Mackintosh, 1977; Terrace, 1966). Milton Trapold, the researcher who introduced the differential-outcome paradigm to experimental psychology nearly 35 years ago, made these very same points. In my view, he had it right.

\section{Background to the Paradigm}

The ability to respond differentially to different environmental events is a basic characteristic of adaptive behavior. Animals need to know when their behavior will have particular consequences (e.g., will be reinforced) and when it will not. Similarly, if reinforcement is available for a certain behavior, but not for others, they need to know which response to make under which conditions. Without these capabilities, behavior would be haphazard at best.

In the simplest instrumental learning situation, discriminative performances develop from three-term contingencies involving a stimulus (S), a response (R), and a reinforcing outcome $(\mathrm{O})$ : $\mathrm{S}-(\mathrm{R}-\mathrm{O})$. Implicit in this schematic is that responding is reinforced by $\mathrm{O}$ when $\mathrm{S}$ is present, but not otherwise. Thus, $\mathrm{S}$ is said to "set the occasion" for R (Skinner, 1953). A schematic that captures reinforcement for different responses in different situations is the following: $\mathrm{S} 1-(\mathrm{R} 1-\mathrm{O})$ and $\mathrm{S} 2-(\mathrm{R} 2-\mathrm{O})$, where " 1 " and " 2 " denote different stimuli or responses. Here, one response, but not the other, is reinforced in the presence of one stimulus, and vice versa in the presence of the other.

These contingencies, as well as more complex ones (e.g., conditional discriminations), routinely generate behavior appropriate to those contingencies. In other words, subjects come to respond primarily when $\mathrm{S}$ is present in the former situation and to respond differentially to S1 and S2 in the latter. From the perspective of learning theory, the important issue has been to determine which associations making up these contingencies are potent. In other words, what is learned in discrimination tasks?

Thorndike (1911), Hull (1943), and others (e.g., Guthrie, 1935; Spence, 1956) characterized discrimination learning as the development of S-R associations: learning which response goes with a particular stimulus. The reinforcing outcome $(\mathrm{O})$ was mostly considered to be just a catalyst for this associative reaction. By this view, the appropriate learning schematic is $(\mathrm{S}-\mathrm{R})-\mathrm{O}$. With the notable exception of Tolman $(1932,1933)$, provisions for learning about the outcome in its relation to the response that produced it and/or to the stimulus that signaled its availability took the proverbial back seat. Nevertheless, often overlooked is the fact that Thorndike (1911, pp. 98-116) himself initially believed that instrumental learning also involved learning about the rein- forcer, although he maintained an $\mathrm{S}-\mathrm{R}$ view because his experimental data did not compel him to do otherwise. Similarly, Hull's early papers (e.g., Hull, 1930, 1931) clearly included associative relations involving the reinforcer, and he proposed a behavioral mechanism by which these relations could influence instrumental behavior. Curiously, these ideas were absent from Hull's (1943) well-known book, although they resurfaced later on (Hull, 1952).

The development of two-process theories of learning (e.g., Rescorla \& Solomon, 1967), however, effectively underscored how associations between stimuli and the outcomes they signal ( $\mathrm{S}-\mathrm{O}$ relations) could affect instrumental performance. These relations were initially thought to empower those stimuli with nonspecific (motivational) effects that could either energize or depress instrumental behavior, depending on the hedonic similarity between the signaled outcome and the reinforcer maintaining performance. Offering a different perspective within this same theoretical genre, Trapold and Overmier (1972; see also Overmier \& Lawry, 1979) made a convincing case that the modus operandi was primarily associative, rather than motivational, in nature. According to them, $\mathrm{S}-\mathrm{O}$ relations generate conditioned reactions with the capacity to act as a cue for subsequent instrumental behavior. In other words, these reactions were thought to provide an additional discriminative stimulus to supplement, or to replace, the nominal discriminative stimuli in the control over behavior. A seminal and, perhaps, the best-known demonstration of this associative effect was reported by Trapold (1970) in an aptly titled article "Are Expectancies Based Upon Different Positive Reinforcing Events Discriminably Different?" (see also Shepp, 1962, 1964). The expectancies to which he referred are the conditioned reactions arising from predictive $\mathrm{S}-\mathrm{O}$ relations highlighted in two-process theory. Trapold's findings, now referred to as the differentialoutcome effect, provided compelling evidence that the reinforcer in instrumental learning is not merely catalytic for other associations but, instead, is part of what is learned in discrimination tasks.

\section{The Differential-Outcome Effect: Behavioral Manifestations}

Trapold (1970, Experiment 1) trained rats on a successive discrimination in which left versus right leverpresses were reinforced in the presence of different auditory stimuli. For one group, the reinforced responses yielded food on trials with one discriminative stimulus and liquid sucrose on trials with the other stimulus. This group learned to perform the correct spatial responses more rapidly than did controls for which the same outcome occurred on all reinforced trials. Trapold argued that his results were not explicable in terms of nonspecific (motivational) effects of the auditory $\mathrm{S}-\mathrm{O}$ relations, because the discrimination required choosing between two response alternatives. Instead, he claimed that the $\mathrm{S}-\mathrm{O}$ relations in the differential-outcome group had gener- 

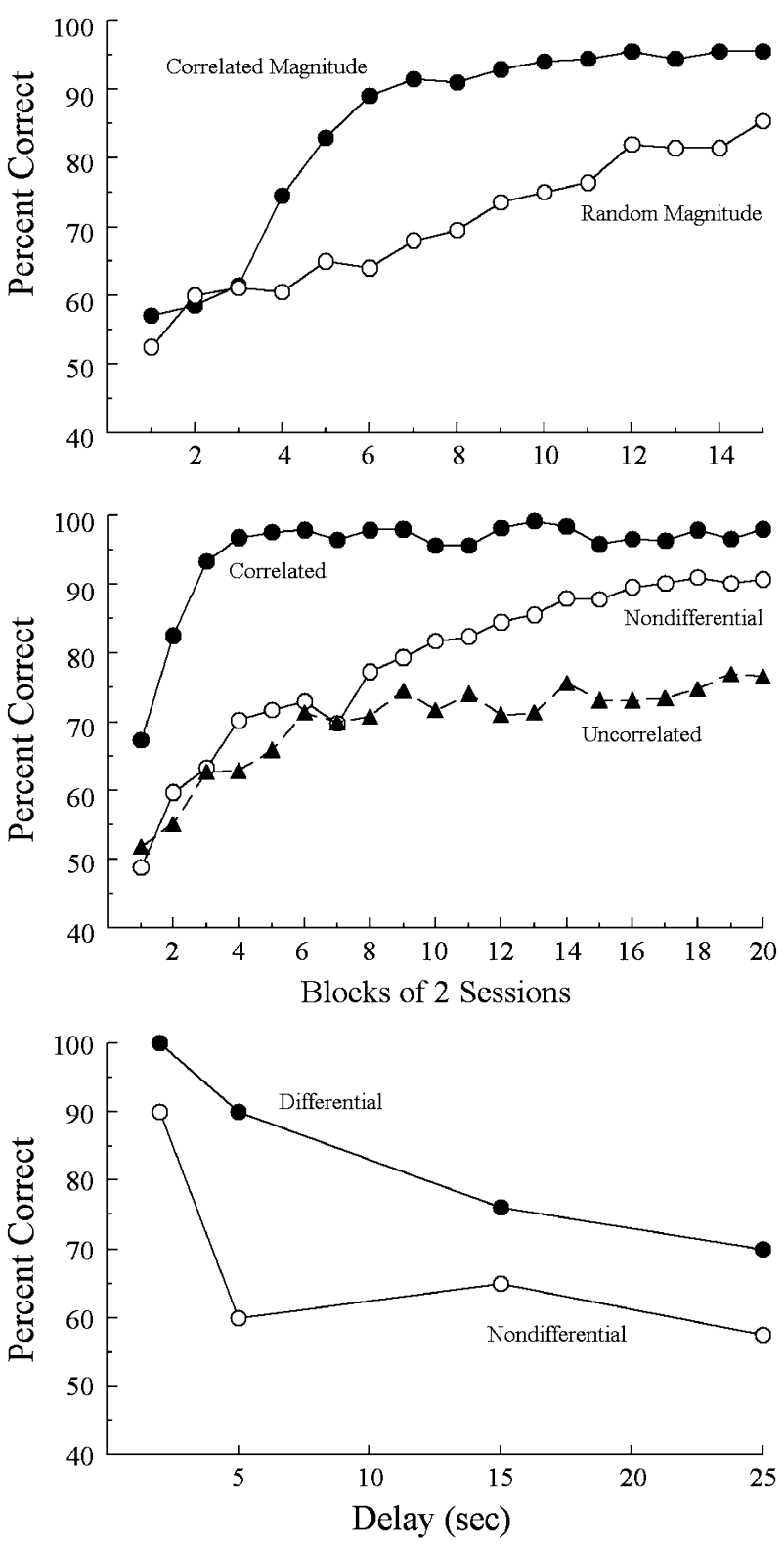

Figure 1. Examples of the differential-outcome effect in rats (top panel), pigeons (middle panel), and adult humans (bottom panel). See the text for details.

ated unique reinforcer expectancies that, in turn, cued which specific leverpress response to make. In other words, this group learned, among other things, to press one lever when expecting food and to press the other lever when expecting sucrose. Controls, on the other hand, could base their responses only on the auditory stimuli themselves. Although the between-group differences Trapold observed could also have arisen by other means (e.g., the groups also differed in terms of the number of reinforcers they experienced), subsequent research has shown that those differences are, indeed, largely attributable to the presence versus the absence of differential $\mathrm{S}-\mathrm{O}$ relations.
The differential-outcome effect is remarkably robust, having been systematically and conceptually replicated across a wide range of conditions, species, and tasks since Trapold's (1970) seminal demonstration (see Figures 1 and 2). The top panel of Figure 1 shows the effect in the acquisition of a two-choice successive discrimination by rats in which two magnitudes of reward, one pellet and five pellets of food, were either correlated with the auditory discriminative stimuli or random with respect to them (Carlson \& Wielkiewicz, 1976). The middle panel shows a differential-outcome effect in the acquisition of a conditional discrimination, symbolic matchingto-sample, by pigeons in which the outcomes for correct comparison responding (food vs. the food hopper light only) were either correlated with or random (nondifferential) with respect to the preceding sample stimuli (Urcuioli, 1991). (The uncorrelated function will be discussed later.) The bottom panel shows another common instantiation of the differential-outcome effect, the facilitation of working memory performances. Here, humans suffering from alcohol-related dementia were more accurate on delayed face recognition when correct recognition of particular male or female faces produced different outcomes (money vs. points), as opposed to each outcome nondifferentially (Hochhalter, Sweeney, Bakke, Holub, \& Overmier, 2000; see also Hochhalter \& Joseph, 2001).

The top panel of Figure 2 shows the effect in aversive conditioning (Overmier, Bull, \& Trapold, 1971) in dogs trained to avoid leg shock by pressing a left or a right panel on which a warning conditioned stimulus (CS) appeared. For two groups, one CS warned of a pulsating shock unconditioned stimulus (UCS) to one leg, whereas the CS appearing on the other panel signaled a constant shock to the other leg. These differential-outcome groups differed from one another in whether the UCS was presented to the leg on the same side as the CS or to the leg on the opposite (crossed) side. Both groups, however, made a higher percentage of avoidance responses than did a mixed (nondifferential) control group for which the type and the location of the imminent UCS were random with respect to the CSs. The middle panel shows a within-subjects differential-outcome effect in the speed with which autistic children learned to correctly choose between two objects upon hearing their spoken names (Litt \& Schreibman, 1981). Criterion levels of accuracy were achieved more quickly when each correct (spoken name-object choice) trial produced a different but equally desirable food (differential) than when the two foods occurred randomly (varied) or when a highly preferred (salient) food followed all correct choices. The bottom panel also shows a within-subjects differential outcome effect in two horses (Miyashita, Nakajima, \& Imada, 2000) trained on a successive two-choice (left vs. right panel press) visual discrimination in which color cues were associated with either different (D) foods, a piece of carrot versus a food pellet, or both foods equally often (ND).

These effects are representative of a literature in which nearly 25 variations of differential outcomes have 

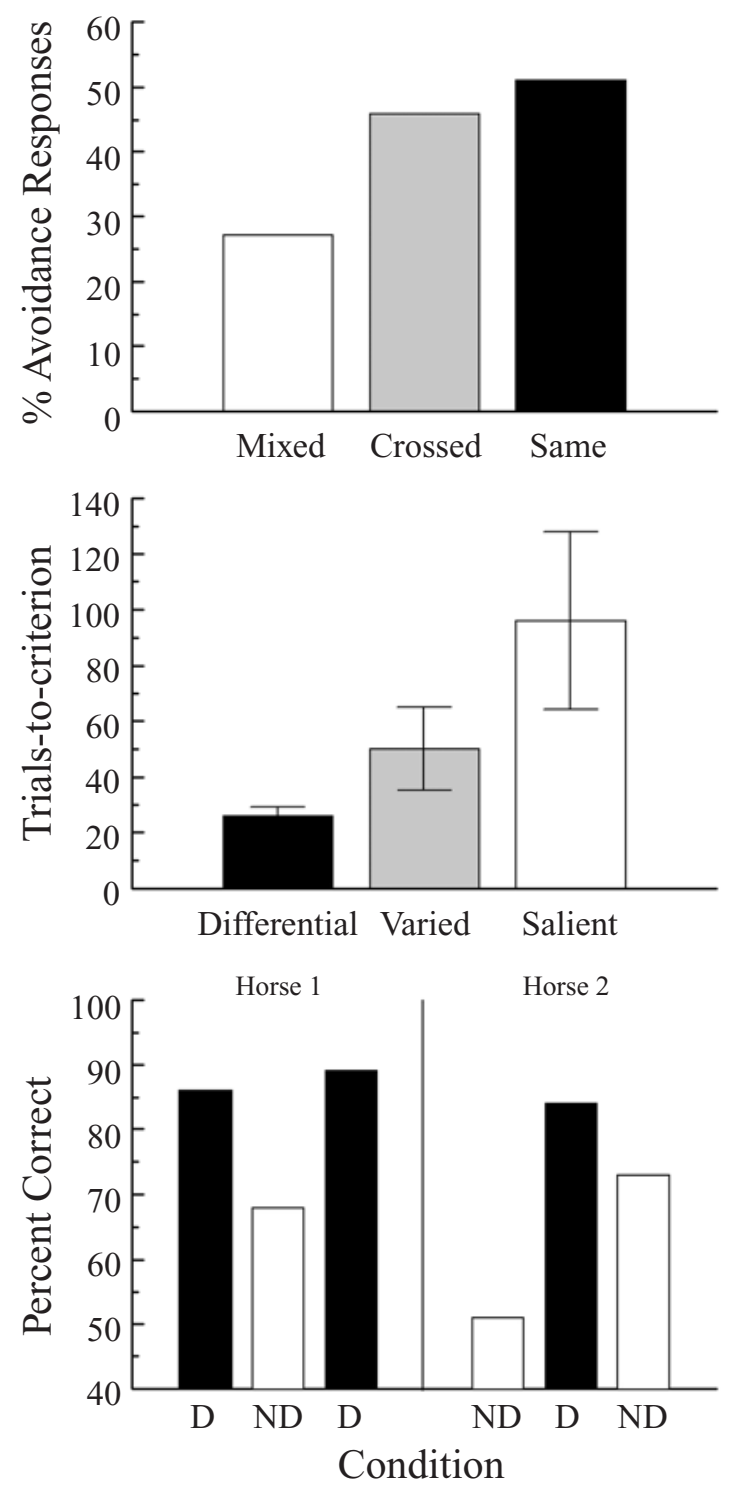

Figure 2. Additional examples of the differential-outcome effect in dogs (top panel), autistic children (middle panel), and horses (bottom panel). See the text for details.

been used in tasks ranging from simple two-choice and go/no-go successive discriminations (e.g., Blundell et al., 2001; Carlson \& Wielkiewicz, 1972; Fedorchak \& Bolles, 1986; Friedman \& Carlson, 1973; Morgan \& Baker, 1997; Papini \& Silingardi, 1989; Urcuioli \& Zentall, 1992) to more complex feature-ambiguous discriminations (Nakajima \& Kobayashi, 2000) and identity and symbolic matching-to-sample (e.g., Alling, Nickel, \& Poling, 1991a, 1991b; Estévez, Fuentes, et al., 2003; Jones, White, \& Alsop, 1995; Saunders \& Sailor, 1979; Urcuioli \& DeMarse, 1996; Zentall \& Sherburne, 1994). Although not always evident in the acquisition of discriminative performance (e.g., Brodigan \& Peterson, 1976; Edwards et al., 1982; Goodwin \& Baker, 2002; Savage, Pitkin, \&
Careri 1999), the effect almost always materializes when a retention interval intervenes between $S$ and $R$ (i.e., in working memory). Indeed, differential-outcome effects are often more pronounced at long than at short retention intervals (e.g., Brodigan \& Peterson, 1976; DeLong \& Wasserman, 1981; Peterson, Linwick, \& Overmier, 1987; Santi \& Roberts, 1985a; Savage, Pitkin, \& Knitowski, 1999; Urcuioli, 1990a; Williams, Butler, \& Overmier, 1990).

The different sensitivities of discrimination acquisition versus steady-state working memory performances to differential outcomes are understandable from an associative view. During acquisition, subjects learn not only which response to make to each stimulus (S-R learning), but also which reinforcing outcome is scheduled on each trial (S-O learning). In order for the latter to influence performance, any cue arising from the learned $\mathrm{S}-\mathrm{O}$ relations must develop prior to performance asymptote. Otherwise, a ceiling effect will obscure its impact. This means that acquisition effects should be more likely when the discrimination task is relatively difficult (i.e., when learning based solely on $\mathrm{S}-\mathrm{R}$ relations is relatively slow; Miller, Waugh, \& Chambers, 2002), but less likely if the task is relatively easy (e.g., in drug discriminations where the nominal discriminative stimuli are particularly distinctive; Goodwin \& Baker, 2002). By contrast, working memory performances should routinely reveal differential-outcome effects because (1) the S-O relations are generally learned by the time retention intervals are introduced and (2) a delay between $S$ and $R$ tends to move accuracy off the ceiling in the nondifferential control group(s) against which differential-outcome performances are compared.

These considerations suggest that pretraining the $\mathrm{S}-\mathrm{O}$ relations prior to introducing the instrumental $(\mathrm{S}-\mathrm{R})$ contingencies should promote a differential-outcome effect in acquisition. Although such pretraining is common to many differential-outcome studies, only one (Ramos \& Savage, 2003, Experiment 2) has explicitly employed it as an independent variable. As was predicted, acquisition was enhanced with differential-outcome pretraining, but not without it.

The associative view also predicts that outcomes differing substantially from one another should enhance differential-outcome effects because (1) they should support faster learning of the $\mathrm{S}-\mathrm{O}$ relations and (2) the resulting conditioned reactions should be relatively distinctive. Although there are no unconfounded tests of this prediction, the available data are consistent with it (e.g., Urcuioli, 1990a).

\section{Source(s) of the Differential-Outcome Effect}

Figures 1 and 2 indicate that the correlation between discriminative stimuli and outcomes is the important variable underlying the differential-outcome effect (cf. Trapold, 1970). By what mechanism, then, do differential $\mathrm{S}-\mathrm{O}$ relations enhance performance?

As was mentioned earlier, Trapold (1970) proposed that those relations generate outcome-specific expectan- 
Table 1

A Schematic of the Various Components and Reinforcement Relations in Differential- Versus Nondifferential-Outcome Discrimination Training

\begin{tabular}{cc}
\hline Differential & Nondifferential \\
\hline $\mathrm{S} 1-\mathrm{E} 1 \rightarrow(\mathrm{R} 1 \rightarrow \mathrm{O} 1)$ & $\mathrm{S} 1-\mathrm{E} 1 / \mathrm{E} 2 \rightarrow(\mathrm{R} 1 \rightarrow \mathrm{O} 1 / \mathrm{O} 2)$ \\
$\mathrm{S} 2-\mathrm{E} 2 \rightarrow(\mathrm{R} 2 \rightarrow \mathrm{O} 2)$ & $\mathrm{S} 2-\mathrm{E} 1 / \mathrm{E} 2 \rightarrow(\mathrm{R} 2 \rightarrow \mathrm{O} 1 / \mathrm{O} 2)$ \\
\hline
\end{tabular}

Note-S1 and S2, discriminative stimuli; R1 and R2, reinforced responses; $\mathrm{O} 1$ and $\mathrm{O} 2$, outcomes contingent upon responding; $\mathrm{E} 1$ and $\mathrm{E} 2$, expectancies of $\mathrm{O} 1$ and $\mathrm{O} 2$, respectively.

Table 2

An Experimental Design to Assess the Acquired Distinctiveness Interpretation of the Differential-Outcome Effect

\begin{tabular}{cc}
\hline Differential-Uncorrelated & Nondifferential \\
\hline $\mathrm{S} 1 \rightarrow(\mathrm{R} 1 \rightarrow \mathrm{O} 1)$ & $\mathrm{S} 1 \rightarrow(\mathrm{R} 1 \rightarrow \mathrm{O} 1 / \mathrm{O} 2)$ \\
$\mathrm{S} 2 \rightarrow(\mathrm{R} 2 \rightarrow \mathrm{O} 2)$ & $\mathrm{S} 2 \rightarrow(\mathrm{R} 2 \rightarrow \mathrm{O} 1 / \mathrm{O} 2)$ \\
$\mathrm{S} 3 \rightarrow(\mathrm{R} 1 \rightarrow \mathrm{O} 2)$ & $\mathrm{S} 3 \rightarrow(\mathrm{R} 1 \rightarrow \mathrm{O} 1 / \mathrm{O} 2)$ \\
$\mathrm{S} 4 \rightarrow(\mathrm{R} 2 \rightarrow \mathrm{O} 1)$ & $\mathrm{S} 4 \rightarrow(\mathrm{R} 2 \rightarrow \mathrm{O} 1 / \mathrm{O} 2)$ \\
\hline
\end{tabular}

Note-S1 and S2, discriminative stimuli; R1 and R2, reinforced responses; $\mathrm{O} 1$ and $\mathrm{O} 2$, outcomes contingent upon responding.

cies conditioned to the nominal discriminative stimuli. Once conditioned, these expectancies acquire stimulus control over instrumental performance in the same manner as would any other discriminative cue: Different responses reinforced in the presence of different stimuli (e.g., outcome expectancies) come under the control of those stimuli. The important assumption here is that outcome expectancies, whatever they may be, have distinctive stimulus properties (cf. Hull, 1931; Trapold, 1970).

Table 1 summarizes this account. E1 and E2 represent the expectancies of the $\mathrm{O} 1$ and $\mathrm{O} 2$ outcomes, respectively, that are conditioned to the discriminative stimuli, $\mathrm{S} 1$ and $\mathrm{S} 2$, in differential-outcome training. Thus, there are two potential cues to control responding: the nominal discriminative stimuli themselves ( $\mathrm{S} 1 \mathrm{vs.}$ S2) and the outcome expectancies (E1 vs. E2) they generate. By contrast, only one cue (S1 vs. S2) can guide responding that is reinforced by each outcome nondifferentially. The "E1/E2" in the Nondifferential column shows that even if animals anticipate uncertain outcomes, that anticipation is the same no matter how the trial begins and, thus, cannot provide a reliable cue for which response to make.

A related mechanism by which differential-outcome expectancies could enhance performances is by providing a particularly salient cue for those performances (Urcuioli, 1990a; cf. Peterson et al., 1987). This account is based on the supposition that any relatively salient cue will support faster learning and/or higher levels of asymptotic performance than a less salient cue will, whether those cues come from the same or from different stimulus dimensions. With certain types of outcomes, outcome expectancies appear to overshadow the nominal discriminative stimuli in the control over instrumental performance (Urcuioli, 1990a, Experiment $2 \mathrm{~B}$ ), a finding that supports the salience difference interpretation (Honig, Matheson, \& Dodd, 1984; Miles \& Jenkins, 1973). But independently of whether the differential-outcome effect reflects the impact of two cues versus one, a more versus a less salient cue, or both in concert, the common feature to all is that they posit another (outcome expectancy) cue to explain the effect.

An entirely different account, however, is one that claims that the differential-outcome effect arises because the different $\mathrm{S}-\mathrm{O}$ relations enhance attention to the nominal discriminative stimuli themselves. This acquired distinctiveness explanation makes no appeal to an additional cue but, instead, postulates the potentiation of stimulus control by the nominal stimuli when they signal different outcomes.

Jones et al. (1995) evaluated this alternative in pigeons' delayed matching-to-sample by arranging that two hue sample stimuli signaled different reward magnitudes for correct choice on some matching trials but the same (constant) reward magnitude on other trials. Two derived measures were used to compare performances under these two conditions: $\log d_{0}$, sample discriminability with no retention interval, and $b$, the rate of forgetting with increasing retention intervals. Consistent with acquired distinctiveness, $\log d_{0}$ (sample discriminability) was larger on trials in which the hue samples were associated with different reward magnitudes. However, contrary to this account, the rate of forgetting $(b)$ was slower on differential-outcome than on constant-outcome trials. The latter finding raises problems because, if the samples alone controlled performance in both conditions, albeit to varying degrees, their loss of control with increasing retention intervals (b) should be the same despite any difference in their initial level of control $\left(\log d_{0}\right)$. Given that it was not, Jones et al. interpreted the observed differences as evidence that an additional cue (outcome expectancies) controlled performances in the differential magnitude condition (see also Jones \& White, 1994).

Honig et al. (1984) and Urcuioli (1991; see also Urcuioli, 1990a) have also shown that differential outcomes do more than just enhance the control by the stimuli that signal them (see Table 2). In each study, pigeons matched four sample stimuli (S1-S4) to just two comparison responses (R1 and R2). For one group, the reinforcing outcomes $(\mathrm{O} 1$ and $\mathrm{O} 2$, which were food and water in Honig et al., 1984, vs. food and a feeder light in Urcuioli, 1991) occurred equally often (i.e., nondifferentially) on every matching trial. For the other group, the outcomes were differential with respect to the sample stimuli but were uncorrelated with the reinforced responses (e.g., a correct $\mathrm{R} 1$ produced $\mathrm{O} 1$ on some trials but $\mathrm{O} 2$ on other trials, and the same was true for a correct R2). Thus, only the sample stimuli (S) provided a valid cue for responding (R), even in the group trained with differential outcomes.

If samples that signal a unique outcome command stronger attention and this alone is sufficient to produce a differential-outcome effect, the differential-uncorrelated group should learn faster than the nondifferential group. Honig et al. (1984) found no such difference. Urcuioli (1991) actually found slower acquisition by the differentialuncorrelated group than by the nondifferential control 
(cf. the middle panel of Figure 1), a result that clearly contradicts acquired distinctiveness. Indeed, an unembellished acquired distinctiveness account predicts that acquisition in the differential-uncorrelated group should be comparable to acquisition in a group for which outcomes are correlated with both the sample stimuli and the correct responses (i.e., in a differential-correlated condition). Figure 1 shows this not to be the case: Uncorrelated acquisition lagged far behind correlated acquisition, a finding also reported by Honig et al. (1984).

These results are consistent, however, with Trapold's (1970) original interpretation that differential outcomes produce reinforcer-specific expectancies that serve as another discriminative cue for performance. The expectancies in the uncorrelated conditions of Urcuioli (1991) and Honig et al. (1984) would presumably generate conflicting information: When $\mathrm{O} 1$ is expected, $\mathrm{R} 1$ is reinforced on some trials, but R2 is reinforced on other trials. Likewise, when $\mathrm{O} 2$ is expected, $\mathrm{R} 1$ is sometimes reinforced, but on other occasions, R2 is reinforced. Although these conditions might be expected to reduce the influence of E1 and E2 on performance (cf. Wagner, Logan, Haberlandt, \& Price, 1968), the differential-uncorrelated results reported by Urcuioli (1991) suggest that they actually interfere with the ability of valid stimuli (e.g., the samples) to control those same performances (see also Shepp, 1962, 1964, for similar findings). Such interference, by the way, is also consistent with the notion that differential outcome expectancies are especially salient.

At this point, it is worth noting that a common (although not universal) feature of many differential-outcome discriminations is that each reinforced response is also associated with a unique outcome. In other words, $\mathrm{R}-\mathrm{O}$ relations are typically differential, as well as the $\mathrm{S}-\mathrm{O}$ relations. Consequently, it is possible that the different consequent outcomes contingent upon correct responding (differential $\mathrm{R}-\mathrm{O}$ relations), rather than or in addition to the different outcomes anticipated prior to responding (via the differential $\mathrm{S}-\mathrm{O}$ relations), are mostly responsible for the differential-outcome effect. This possibility is made more plausible by data showing that differential outcomes enhance discrimination learning even when the discriminative stimuli, by themselves, do not predict which outcome is available for correct responding (DeMarse \& Urcuioli, 1993; Urcuioli \& DeMarse, 1997). Stated otherwise, even when the $\mathrm{S}-\mathrm{O}$ relations are nondifferential, discrimination learning is enhanced when the correct responses produce different outcomes. I will address the issue of the relative contributions of $\mathrm{R}-\mathrm{O}$ and $\mathrm{S}-\mathrm{O}$ relations to the differential-outcome effect more fully later on. For now, however, it is important only to note that these sorts of data present a challenge to the associative two-process view originally proposed by Trapold (1970; see also Overmier \& Lawry, 1979; Trapold \& Overmier, 1972).

\section{Demonstrating the Cue Properties of Outcome Expectancies}

Mindful that there could be viable alternatives to the associative two-process account, differential-outcome effects in acquisition and/or in working memory are nonetheless mostly consistent with the hypothesized response-cuing properties of outcome expectancies. The associative view gains considerably more credence, however, by data from independent tests of these properties: shifting to a constant outcome or to nondifferential outcomes following differential outcome training, reversing the outcomes associated with each reinforced trial, and assessing the transfer of instrumental responding across different sets of stimuli that signal a common set of differential outcomes.

The associative view predicts that the former two manipulations will disrupt performances, despite continued reinforcement for responding, because these manipulations will either remove the expectancy cue or alter its antecedent relation to reinforced responding. By contrast, discriminative performances should remain largely intact in transfer-of-control tests, because if those performances are truly cued by differential-outcome expectancies, the particular stimuli generating the expectancies should not matter (e.g., Edwards et al., 1982). In other words, the associative view predicts that already learned discriminative responding will immediately be controlled by new stimuli that share the same outcome associations as the stimuli they replace, even if the former have no history of reinforced $(\mathrm{S}-\mathrm{R})$ control over responding.

Outcome shifts and reversals. Changing the outcome contingencies so that each reinforced trial now ends with the same reinforcer, or equally often with each reinforcer, should cause otherwise accurate performances to deteriorate by eliminating the outcome-specific cue. How quickly this effect occurs will depend on whether the shift from differential to nondifferential $\mathrm{S}-\mathrm{O}$ relations is done prior to the test phase or concurrently with it (see, e.g., Peterson \& Trapold, 1980; Urcuioli, 1990a; Urcuioli \& Zentall, 1992). In either case, however, performance should be disrupted following such shifts.

Consistent with this prediction, Chatlosh and Wasserman (1992) reported that discrimination accuracy by pigeons trained on a go/no-go identity-matching task with different probabilities of food reinforcement ( $p=.2 \mathrm{vs}$. 1.0 ) dropped by as much as $33 \%$ when shifted to continuous reinforcement on all matching trials $(p=1.0)$. Note that the shift to constant outcomes actually increased the overall percentage of reinforced trials in a session. Nonetheless, performances deteriorated, attesting to the power of the outcome expectancy cue. Likewise, Peterson, Wheeler, and Armstrong (1978) and Peterson, Wheeler, and Trapold (1980) showed that a shift from differential outcomes to a single (constant) outcome in pigeons' two-choice symbolic matching caused accuracy to drop from $95 \%$ correct to levels ranging from $62 \%$ to $82 \%$. This effect was not seen when nondifferential outcomes were used in training (Peterson et al., 1980, Experiment 1), a finding that rules out the less interesting possibility that any shift from two outcomes to one is disruptive. Matching accuracy by pigeons has also been found to drop substantially with a shift from differential outcomes in training to nondifferential outcomes in testing (Peterson et al., 1978, Experiment 1; Urcuioli, 


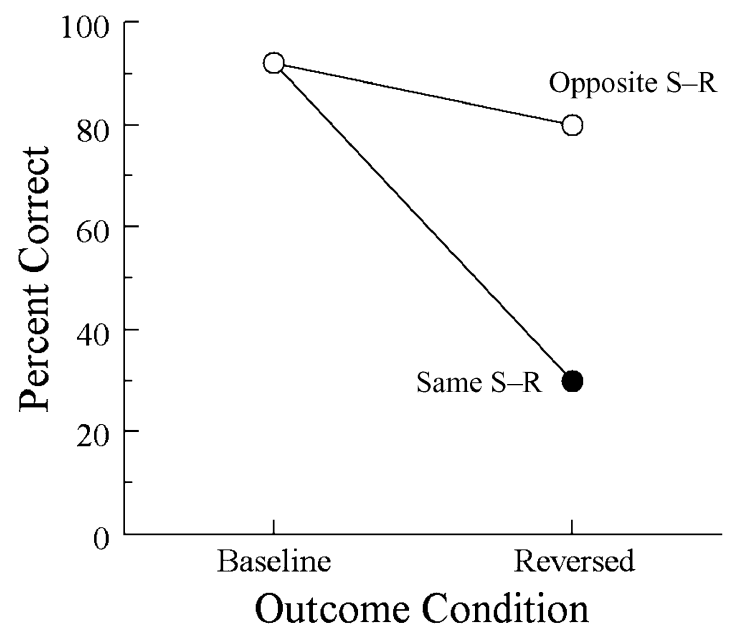

Figure 3. Matching accuracy by pigeons during baseline training with differential outcomes and testing with the outcomes for correct choice reversed. The reinforced choice responses following each sample were either maintained (same $\mathbf{S}-\mathbf{R}$ ) or reversed (opposite S-R) during the outcome reversal. Adapted from Peterson and Trapold (1980).

1990a, 1990b). Here, the number of different outcomes is held constant (at two) throughout training and testing. Only the correlation between outcomes and samples is varied.

There are several permutations of the outcome reversal test. In perhaps the simplest version, the discriminative stimuli occasion the same reinforced responses (i.e., the $\mathrm{S}-\mathrm{R}$ relations are unchanged), but the reinforcing outcome on each trial type is switched. Thus, if correct responses to $\mathrm{S} 1$ and $\mathrm{S} 2$ initially produced $\mathrm{O} 1$ and $\mathrm{O} 2$, respectively, they now produce $\mathrm{O} 2$ and $\mathrm{O} 1$, respectively. Note that if discrimination learning is simply the acquisition of S-R relations, this reversal should have little, if any, effect on performance. By contrast, if reinforcers also enter into associative relations with the stimuli that signal their availability, reversing these $\mathrm{S}-\mathrm{O}$ relations should affect performance - and it typically does (DeLong \& Wasserman, 1981; Peterson \& Trapold, 1982; Peterson et al., 1978, Experiment 2; see also Honig et al., 1984; Urcuioli, DeMarse, \& Lionello-DeNolf, 2001; Urcuioli \& Zentall, 1992, Experiment 4).

Figure 3 provides an example (Peterson \& Trapold, 1980, Experiment 1). The same S-R function shows what happens to performance when the originally trained $\mathrm{S}-\mathrm{O}$ relations are reversed in the context of reinforcing the same sample (S)-comparison-response (R) relations as in training. Accuracy drops dramatically even though the baseline $\mathrm{S}-\mathrm{R}$ relations continue to be reinforced as before. By contrast, the opposite $\mathrm{S}-\mathrm{R}$ function shows that the disruptive effect of the outcome reversal is much weaker when the reinforced comparison response following each sample is also switched during the reversal phase (see also Carlson \& Wielkiewicz, 1976, Experiment 2; Urcuioli \& Zentall, 1992, Experiment 4). The latter test condition involves a much more dramatic change in contingencies, relative to baseline, and yet supports relatively high levels of accuracy.

Table 3 shows that both findings make sense if comparison responding during training had been cued by differential-outcome expectancies. Stimulus control by those expectancies is highlighted by the italicized $\mathrm{E}-\mathrm{R}$ relations in the first column. When the outcomes signaled by S1 and S2 are then reversed, the expectancies also reverse: S1 now generates E2, and S2 now generates E1. Consequently, when the originally reinforced $\mathrm{S}-\mathrm{R}$ relations are maintained in testing (Outcome Reversal column), there is conflicting information about which response to make on each trial: $\mathrm{S} 1$ should cue R1, but E2 should cue R2; similarly, S2 should cue R2, but E1 should cue R1. Assuming that the outcome expectancies are more salient than the samples themselves (Urcuioli, 1990a; see also Peterson et al., 1987), accuracy should drop substantially despite the fact that the reinforced S-R relations remain the same. By contrast, reversal performances should be very accurate when the $\mathrm{S}-\mathrm{R}$ relations are also reversed (Outcome and Response Reversal col$\mathrm{umn}$ ), because this will guarantee that the reinforced E-R relations remain the same as in initial training, as the italicized relations shown in the third column indicate.

Another reversal procedure involves switching outcomes on just half of all discrimination trials, a manipulation predicted to disrupt performance on all trialseven those on which there is no change in outcome contingencies.

One version of the partial reversal (Peterson \& Trapold, 1982; Urcuioli et al., 2001) has the effect of changing differential $\mathrm{S}-\mathrm{O}$ relations in training to nondifferential relations in testing (see Table 4). Here, subjects initially learn a discrimination with just two stimuli (S1 and S2) but with four responses (R1-R4) organized into two pairs (R1 vs. $\mathrm{R} 2$ and R3 vs. R4). During training, S1 signals one outcome (O1) for whichever correct response is available (R1 or R3), and $\mathrm{S} 2$ signals the other outcome (O2) for whichever alternative response is available ( $\mathrm{R} 2$ or $\mathrm{R} 4)$. Later, the outcomes are reversed (changed) for one set of responses (e.g., R3 vs. R4) but remain the same (unchanged) for the other set (e.g., R1 vs. R2). The net result is that S1 and S2 no longer predict $\mathrm{O} 1$ and $\mathrm{O} 2$ : Each outcome occurs equally often on correct trials with each stimulus. Thus, $\mathrm{S} 1$ and S2 can no longer support differential-outcome expectancies, as is shown in the Theoretics portion of the table.

Table 3

A Schematic of Outcome Reversal Manipulations as a Method for Establishing Discriminative Control by Outcome Expectancies

\begin{tabular}{lcc}
\hline \multicolumn{1}{c}{ Initial Training } & Outcome Reversal & $\begin{array}{c}\text { Outcome and } \\
\text { Response Reversal }\end{array}$ \\
\hline $\mathrm{S} 1-E 1 \rightarrow R 1(\mathrm{O} 1)$ & $\mathrm{S} 1-\mathrm{E} 2 \rightarrow \mathrm{R} 1(\mathrm{O} 2)$ & $\mathrm{S} 1-E 2 \rightarrow R 2(\mathrm{O} 2)$ \\
$\mathrm{S} 2-E 2 \rightarrow R 2(\mathrm{O} 2)$ & $\mathrm{S} 2-\mathrm{E} 1 \rightarrow \mathrm{R} 2(\mathrm{O} 1)$ & $\mathrm{S} 2-E 1 \rightarrow R 1(\mathrm{O} 1)$ \\
\hline
\end{tabular}

Note-S1 and S2, discriminative stimuli; R1 and R2, reinforced responses; $\mathrm{O} 1$ and $\mathrm{O} 2$, outcomes contingent upon responding; $\mathrm{E} 1$ and $\mathrm{E} 2$, expectancies of $\mathrm{O} 1$ and $\mathrm{O} 2$, respectively. 
Table 4

Changing S-O Relations from Differential to Nondifferential by Reversing the Outcomes for Correct Responding on One Half of the Discrimination Trials (a Partial Outcome Reversal)

\begin{tabular}{ll}
\hline Initial Training & Partial Outcome Reversal \\
\hline $\mathrm{S} 1 \rightarrow \mathrm{R} 1(\mathrm{O} 1)$ & $\mathrm{S} 1 \rightarrow \mathrm{R} 1(\mathrm{O} 1)$ \\
$\mathrm{S} 2 \rightarrow \mathrm{R} 2(\mathrm{O} 2)$ & $\mathrm{S} 2 \rightarrow \mathrm{R} 2(\mathrm{O} 2)$ \\
& \\
$\mathrm{S} 1 \rightarrow \mathrm{R} 3(\mathrm{O} 1)$ & $\mathrm{S} 1 \rightarrow \mathrm{R} 3(\mathrm{O} 2) \quad$ changed \\
$\mathrm{S} 2 \rightarrow \mathrm{R} 4(\mathrm{O} 2)$ & $\mathrm{S} 2 \rightarrow \mathrm{R} 4(\mathrm{O} 1)$
\end{tabular}

Theoretics

$\mathrm{S} 1-\mathrm{E} 1 \ldots \mathrm{S} 1-\mathrm{E} 1 / \mathrm{E} 2 \ldots$

$\mathrm{S} 2-\mathrm{E} 2 . . \quad \mathrm{S} 2-\mathrm{E} 1 / \mathrm{E} 2$.

Note- $\mathrm{S} 1$ and $\mathrm{S} 2$, discriminative stimuli; R1 and R2, reinforced responses; $\mathrm{O} 1$ and $\mathrm{O} 2$, outcomes contingent upon responding; $\mathrm{E} 1$ and $\mathrm{E} 2$, expectancies of $\mathrm{O} 1$ and $\mathrm{O} 2$, respectively.

Table 5

Changing the Validity of an Outcome Expectancy Cue by Reversing the Outcomes for Correct Responding on Half of the Discrimination Trials (a Partial Outcome Reversal)

\begin{tabular}{lc}
\hline Initial Training & Partial Outcome Reversal \\
\hline $\mathrm{S} 1 \rightarrow \mathrm{R} 1(\mathrm{O} 1)$ & $\mathrm{S} 1 \rightarrow \mathrm{R} 1(\mathrm{O} 1)$ \\
$\mathrm{S} 2 \rightarrow \mathrm{R} 2(\mathrm{O} 2)$ & $\mathrm{S} 2 \rightarrow \mathrm{R} 2(\mathrm{O} 2)$ \\
$\mathrm{S} 3 \rightarrow \mathrm{R} 1(\mathrm{O} 1)$ & $\mathrm{S} 3 \rightarrow \mathrm{R} 1(\mathrm{O} 2)$ \\
$\mathrm{S} 4 \rightarrow \mathrm{R} 2(\mathrm{O} 2)$ & $\mathrm{S} 4 \rightarrow \mathrm{R} 2(\mathrm{O} 1)$ \\
& \\
$\mathrm{E} 1 \rightarrow \mathrm{R} 1$ & changed \\
$\mathrm{E} 2 \rightarrow \mathrm{R} 2$ & $\mathrm{E} 1 \rightarrow \mathrm{R} 1$ or R2 \\
\end{tabular}

Note-S1-S4, discriminative stimuli; R1 and R2, reinforced responses; $\mathrm{O} 1$ and $\mathrm{O} 2$, outcomes contingent upon responding; $\mathrm{E} 1$ and $\mathrm{E} 2$, expectancies of $\mathrm{O} 1$ and $\mathrm{O} 2$, respectively.

Table 5 shows another kind of partial reversal (Honig et al., 1984, Experiment 2) in which the S-O relations remain differential throughout training and testing but the outcome expectancies change from being a valid to being an invalid cue. Here, subjects initially learn to make each of two responses (R1 and R2) to different stimuli ( $\mathrm{S} 1$ and $\mathrm{S} 3$, and $\mathrm{S} 2$ and $\mathrm{S} 4$, respectively). Initially, $\mathrm{O} 1 \mathrm{oc}-$ curs on all trials on which R1 is the correct response (viz., $\mathrm{S} 1$ and $\mathrm{S} 3$ trials), and $\mathrm{O} 2$ occurs on all trials on which R2 is correct (viz., S2 and S4 trials). Thus, no matter which stimulus gives rise to it, E1 can cue R1 and E2 can cue R2 in training. Later, the outcomes occurring on the S3 and S4 trials are reversed (changed). The consequence of this is that even though S3 and S4 will continue to generate different outcome expectancies, those expectancies no longer provide a valid cue for responding on any trial, including those on which the outcome contingencies are unchanged. The reason for this is that across all four trial types, E1 and E2 precede each reinforced response equally often.

Both partial reversal procedures, then, should disrupt performances on unchanged trials, as well as on changed trials. Figure 4 shows that this is precisely what occurs. The top and bottom panels present data, respectively, from each of the reversal manipulations described above (Honig et al., 1984; Urcuioli et al., 2001).
Transfer of control. Perhaps the clearest and most convincing evidence for discriminative control by outcome expectancies is the finding that other stimuli will immediately control the baseline performances, despite no reinforced history of doing so, if they signal the same differential outcomes as the training stimuli. Stated otherwise, responding initially learned to one set of stimuli will transfer to another set that shares the same outcome associations. Although transfer-of-control designs vary in their procedural structure, the underlying rationale is the same: Any observed transfer cannot be explained simply in terms of the nominal test stimuli but must appeal to the associative properties of those stimuli-in particular, their relations to the reinforcing outcomes (i.e., $\mathrm{S}-\mathrm{O}$ relations).

Table 6 shows a typical transfer design (Honig et al., 1984; Kruse, Overmier, Konz, \& Rokke, 1983; Maki, Overmier, Delos, \& Gutmann, 1995; Peterson, 1984; Urcuioli, 1990a; Urcuioli \& DeMarse, 1996) and its underlying theoretics. Differential-outcome discrimination training is followed by a phase in which two new stimuli (S3 and S4) are differentially paired with the training outcomes (O1 and $\mathrm{O} 2)$. The response alternatives are unavailable during the pairing phase, to preclude the possibility that responding will come under direct (reinforced) control of S3 and S4. In testing, however, those alternatives are again made available, and preferences for one response over another are measured in the presence of each "new" stimulus.

If discriminative responding during training was cued, at least in part, by the outcome expectancies (E1 and E2) conditioned to the training (S1 and S2) stimuli, R1 and R2 should occur preferentially to S3 and S4, respectively, in transfer, because those test stimuli should also generate E1 and E2. Conversely, if discrimination learning solely involves the acquisition of S-R relations, no such preferences should be observed, given that R1 and R2 have never been reinforced following S3 and S4. A purely motivational account of the impact of S-O relations on instrumental performance also predicts no preference: R1 and R2 should be equally enhanced (or depressed) by each test stimulus.

In fact, as Figure 5 shows, clear preferences are routinely observed in these types of tests. In the study with rats (Kruse et al., 1983), different auditory stimuli signaled that left versus right leverpresses would produce food versus a sugar solution, respectively, in training on either a continuous or a partial reinforcement schedule. Subsequently, a third auditory stimulus (CS+) was paired with one of the two outcomes in the absence of the levers. When the CS + was then presented with both levers available, rats preferred to press the lever that, in discrimination training, had been reinforced with the same outcome as that signaled by the CS + .

In the study with humans (Maki et al., 1995), young children learned symbolic matching-to-sample in which two samples signaled that correct responding would produce different colored tokens exchangeable for food versus toys. Later, two novel stimuli were differentially paired 

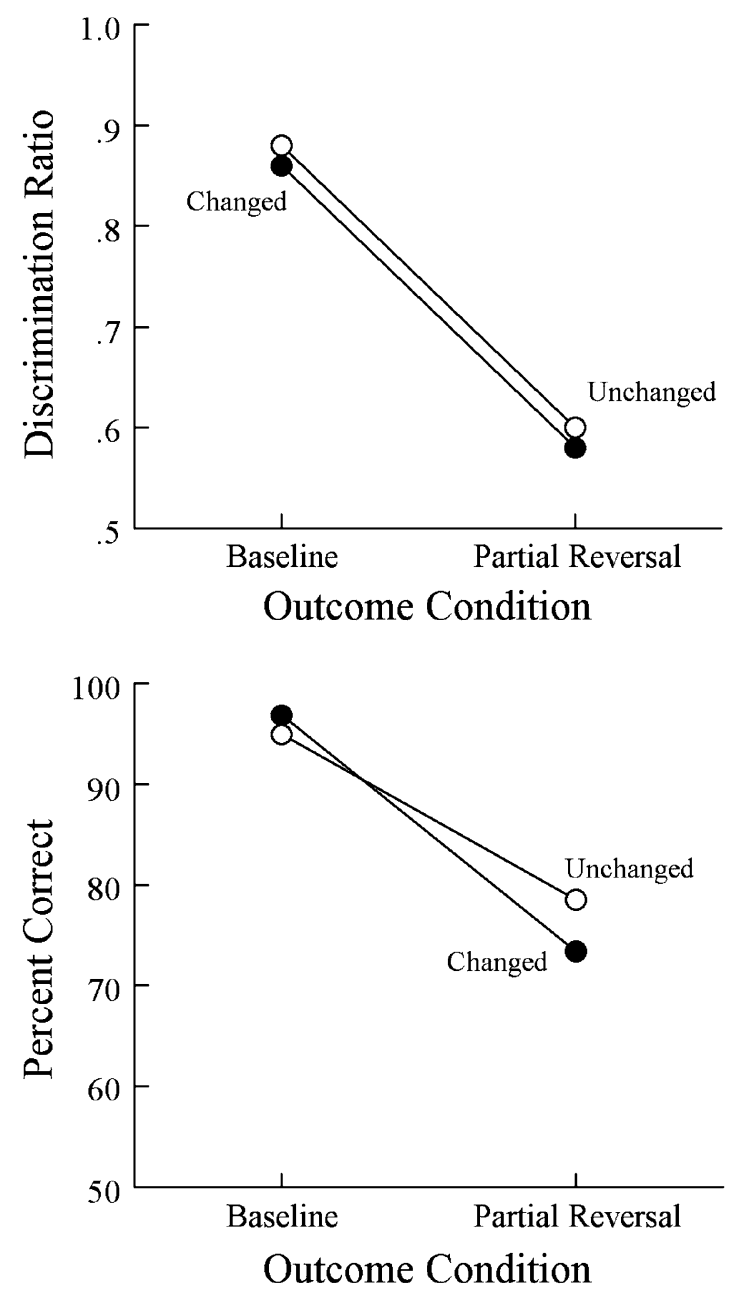

Figure 4. Successive (top panel) and two-choice (bottom panel) symbolic matching accuracy by pigeons during differential outcome training (baseline) and after the outcomes scheduled for two of the four sample trial types were reversed (partial reversal). Changed, trials on which outcomes were reversed; unchanged, trials on which outcomes were not reversed. Adapted from Honig, Matheson, and Dodd (1984) and Urcuioli, DeMarse, and Lionello-DeNolf (2001).

with the (token + primary reinforcer) combinations, after which they replaced the original samples in the matching task. Children were highly accurate (i.e., showed positive transfer of their comparison choices) when each novel sample replaced the one from original training that signaled the same outcome. By contrast, control subjects for whom nondifferential outcomes had been scheduled during the symbolic matching and/or during the pairing phase were substantially less accurate when tested on the same reinforced relations. Thus, the samples appearing in testing were substitutable for the training samples in their control over matching only if both sets had been associated with different outcomes.

In the studies with pigeons (Urcuioli, 1990a), they were initially trained on symbolic matching with either differential (D) or nondifferential (N) outcomes, which was then followed for all birds by off-baseline training in which two new stimuli were differentially (D) paired with the two outcomes used in the matching task. Those new stimuli then replaced the samples in symbolic matching. When differential outcomes were used throughout training (DD), the reinforced response following each novel sample in testing was identical to that reinforced after the training sample that signaled the same outcome. The birds in this condition chose more accurately during transfer than did the birds in the ND condition that were tested identically. Moreover, the degree of positive transfer in the former group varied as a function of the nature of the outcomes. Transfer was relatively small when the outcomes were different probabilities of food (viz., 1.0 vs. .2) but was quite substantial when they were food versus the feeder light only.

To reiterate, these transfer effects cannot be explained simply in terms of S-R learning. First of all, even if there were stimulus generalization (Honig \& Urcuioli, 1981) between the stimuli used in training and those appearing in testing, that alone would produce comparable levels of performances, not different ones, across the groups/conditions in testing. Second, the test stimuli had no prior reinforcement history of controlling the reinforced responses in transfer, so the S-R test relations by themselves should support preferences/accuracies only in the range of $50 \%$, not at the above-chance levels exhibited in the differential training conditions. The results are explicable, however, if outcome expectancies had acquired control over responding during differential-outcome training, so that those same responses could be cued by those same expectancies in testing (Edwards et al., 1982; Honig et al., 1984; Peterson, 1984; Urcuioli \& Zentall, 1992, Experiment 2; see also Blundell et al., 2001; Colwill \& Rescorla, 1988).

\section{Nature of the Outcome Expectancy Cue}

If different conditioned reactions (expectancies) develop to stimuli signaling different outcomes, what are those conditioned reactions, and do they behave in a way that associative two-process theory says that they should? Specifically, do they provide a source of stimulation to direct instrumental behavior?

Table 6

A Typical Transfer-of-Control Design to Evaluate the Discriminative Properties of Outcome Expectancies

\begin{tabular}{ccl}
\hline Discrimination Training & Pairing & \multicolumn{1}{c}{ Transfer Test } \\
\hline $\mathrm{S} 1 \rightarrow \mathrm{R} 1(\mathrm{O} 1)$ & $\mathrm{S} 3 \rightarrow \mathrm{O} 1$ & $\mathrm{~S} 3 \rightarrow \mathrm{R} 1$ vs. R2 \\
$\mathrm{S} 2 \rightarrow \mathrm{R} 2(\mathrm{O} 2)$ & $\mathrm{S} 4 \rightarrow \mathrm{O} 2$ & $\mathrm{~S} 4 \rightarrow \mathrm{R} 1$ vs. R2 \\
& Theoretics & \\
& S3-E1 & S3-E1 $\rightarrow$ R1 vs. R2 \\
$\mathrm{S} 1-\mathrm{E} 1 \rightarrow \mathrm{R} 1$ & $\mathrm{~S} 4-\mathrm{E} 2$ & $\mathrm{~S} 4-\mathrm{E} 2 \rightarrow \mathrm{R} 1$ vs. R2 \\
$\mathrm{S} 2-\mathrm{E} 2 \rightarrow \mathrm{R} 2$ &
\end{tabular}

Note-S1-S4, discriminative stimuli; R1 and R2, reinforced responses; $\mathrm{O} 1$ and $\mathrm{O} 2$, outcomes; $\mathrm{E} 1$ and $\mathrm{E} 2$, expectancies of $\mathrm{O} 1$ and $\mathrm{O} 2$, respectively. Underlining indicates the preferred response if outcome expectancies control performance. 

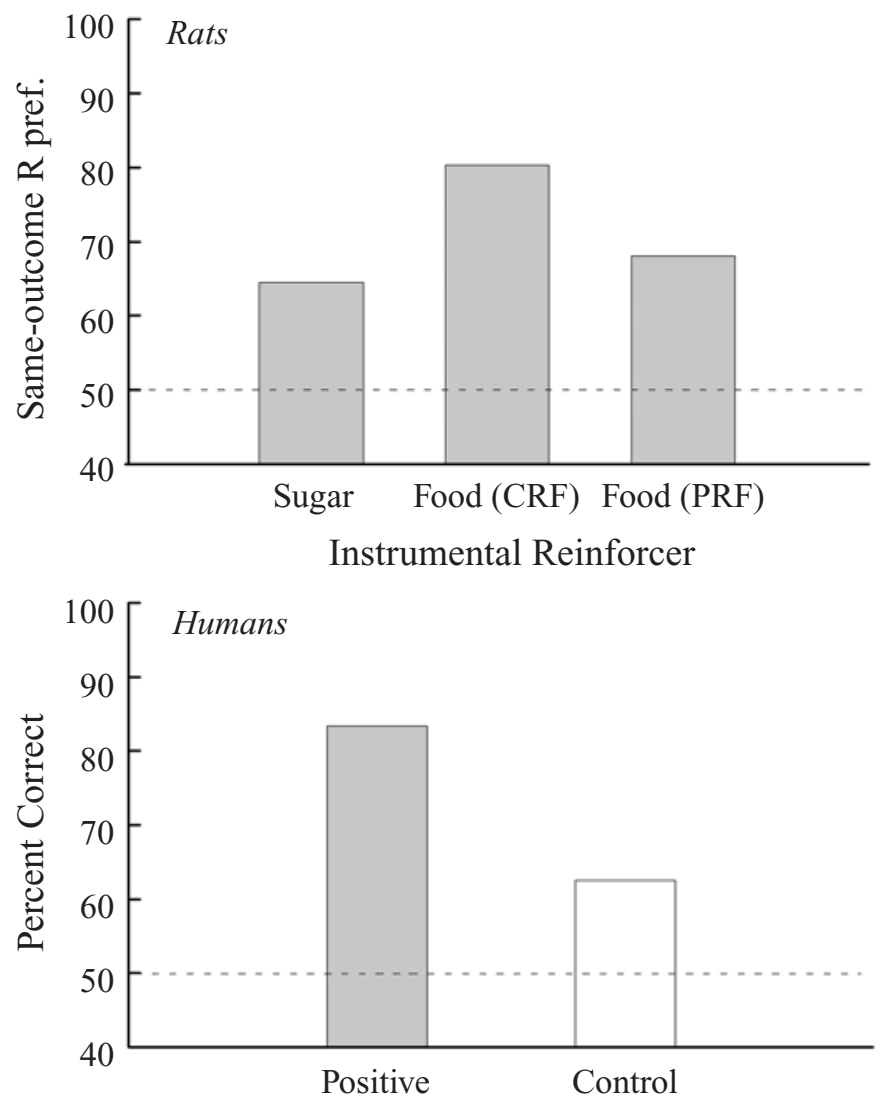

Transfer Condition

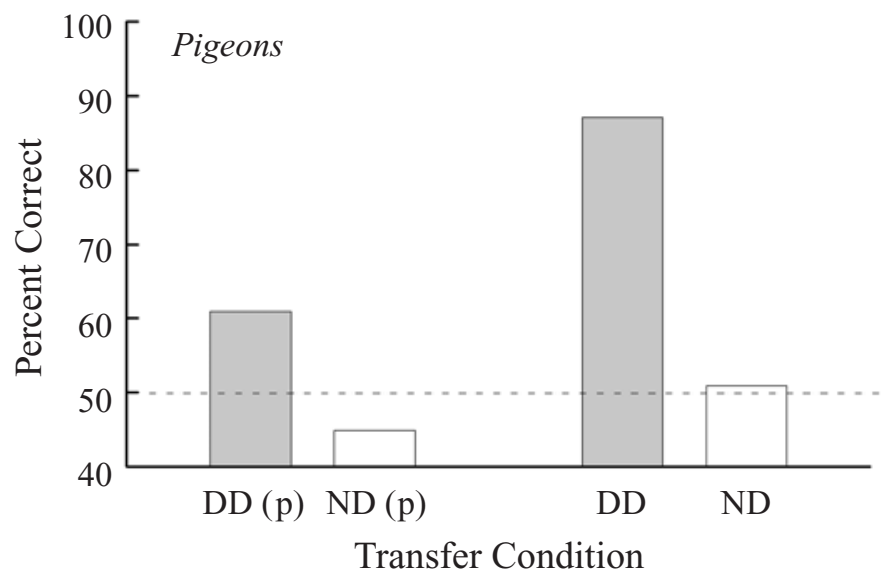

Figure 5. Examples of transfer of differential-outcome discriminative performances to new stimuli paired with the outcomes used in training. Horizontal dotted lines represent chance levels of performance. See the text for details.

In some differential-outcome paradigms, pigeons exhibit topographically different responses, or respond in different patterns or rates, to the stimuli that signal different outcomes. For instance, when food and water are used as outcomes in symbolic matching (e.g., Brodigan $\&$ Peterson, 1976; Honig et al., 1984), peck topographies characteristic of food versus water responding develop to the samples (Jenkins \& Moore, 1973). When samples signal different probabilities of food for correct responding, pecking often occurs at a higher rate to the highprobability than to the low-probability sample (e.g., Alling et al., 1991a; DeLong \& Wasserman, 1981; Santi \& Roberts, 1985b; Urcuioli, 1990a, 1990b). When the outcomes are food versus the food hopper light only ("no 
Table 7

\begin{tabular}{|c|c|c|}
\hline \multicolumn{3}{|c|}{$\begin{array}{l}\text { A Transfer-of-Control Design and Theoretics for Evaluating Cue Properties } \\
\text { of Differential Responding Versus Outcome Expectancies Conditioned to } \\
\text { Stimuli Signaling Differential Outcomes (Urcuioli \& DeMarse, 1994) }\end{array}$} \\
\hline Differential Outcome Training & Pairing & Transfer Test \\
\hline $\mathrm{S} 1 \rightarrow \mathrm{R} 1$ & $\mathrm{~S} 3 \cdot \mathrm{FI}$ & - FI $\rightarrow$ R1 (food) \\
\hline $\mathrm{S} 2 \rightarrow \mathrm{R}$ & $\mathrm{S} 4 \cdot \mathrm{DRO}$ & $\mathrm{S} 4 \cdot \mathrm{DRO} \rightarrow$ \\
\hline \multicolumn{3}{|c|}{ Response-Based Theoretics } \\
\hline $\mathrm{S} 1-$ pecking $\rightarrow \mathrm{R} 1$ & S3-pecking & $\mathrm{S} 3$ - pecking $\rightarrow \underline{\mathrm{R} 1}$ vs. R2 \\
\hline $\mathrm{S} 2$ - no pecking $\rightarrow \mathrm{R} 2$ & S4-no pecking & $\mathrm{S} 4-$ no pecking $\rightarrow \mathrm{R} 1$ vs. $\underline{\mathrm{R} 2}$ \\
\hline \multicolumn{3}{|c|}{ Expectancy-Based Theoretics } \\
\hline $\mathrm{S} 1-\mathrm{E}_{\text {food }} \rightarrow \mathrm{R} 1$ & & $\mathrm{~S} 3-\mathrm{E}_{\text {food }} \rightarrow \underline{\mathrm{R} 1}$ vs. R2 \\
\hline $\mathrm{S} 2-\mathrm{E}_{\text {no food }} \rightarrow \mathrm{R} 2$ & $\mathrm{~S} 4-\mathrm{E}_{\text {food }}$ & $\mathrm{S} 4-\mathrm{E}_{\text {food }} \rightarrow \underline{\mathrm{R} 1}$ vs. R2 \\
\hline
\end{tabular}

Note-S1-S4, discriminative stimuli; R1 and R2, reinforced responses; FI, fixedinterval schedule; DRO, differential reinforcement-of-other-behavior schedule; E, expectancy. Underlining indicates the preferred response if differential responses or outcome expectancies control performance.

food"), pigeons routinely peck the food-associated sample but rarely peck the no-food-associated sample (e.g., Peterson, 1984; Urcuioli, 1990a; Urcuioli \& DeMarse, 1996; see also Zentall, Clement, Bhatt, \& Allen, 2001).

Observing these different conditioned reactions, however, is no assurance that they provide the additional cue postulated by Trapold's (1970) account. Another explanation for them is that they are simply another, albeit peripheral, manifestation of more central (expectancy) states from which the functional cue originates (Peterson, 1984; see also Rescorla \& Solomon, 1967). From this perspective, the differential-outcome effect should sometimes be apparent even in the absence of any overt differential behavior to the signaling stimuli. This prediction is supported by data showing enhanced discrimination acquisition under precisely these conditions (e.g., DeMarse \& Urcuioli, 1993; Urcuioli \& DeMarse, 1997; Zentall \& Sherburne, 1994; see also Kelly \& Grant, 2001). Additional corroborative evidence comes from studies in which transfer of control has been observed between samples that signal two different types of food (Edwards et al., 1982; see also Sherburne \& Zentall, 1995) or even two different locations from which to obtain the same food (Friedrich \& Zentall, 2004). Here, the likelihood that subjects would respond in overtly different ways to the sample stimuli is reduced.

Nevertheless, when overt differential sample behavior is present, a good functional analysis ought to encourage the examination of the potential role such behavior may play in the control over subsequent discriminative performance. After all, differential sample behavior conditioned via operant reinforcement exerts demonstrable and powerful control over pigeons' comparison choice responses in matching tasks (Urcuioli, 1984; Urcuioli \& Honig, 1980).

Urcuioli and DeMarse (1994) showed that the overt behavior conditioned via Pavlovian means to the samples in differential-outcome symbolic matching does cue subsequent comparison choice. Moreover, they showed that this effect cannot be explained in terms of a more central outcome expectancy cue. Their experimental design is shown in Table 7, along with two contrasting sets of the theoretics, one assuming discriminative control by the birds' sample behavior and the other assuming outcome expectancy control. Following matching training with food versus no-food (feeder light only) outcomes in which pecking routinely occurred to the sample signaling food, but seldom to the sample signaling no food, the pigeons were trained to respond differentially to two new stimuli (S3 and S4) by explicitly reinforcing (with food) pecking versus not-pecking on fixed-interval and differential-reinforcement-of-other-behavior schedules, respectively. Afterward, S3 and S4 were substituted for the $\mathrm{S} 1$ and $\mathrm{S} 2$ samples in the matching task with all correct responses producing food. The theoretics show that if pecking versus not pecking the samples had cued the $\mathrm{R} 1$ and $\mathrm{R} 2$ responses in training, preference for each response should vary by sample during testing. By contrast, if the functional cue in training arose from food versus no-food expectancies, pigeons should consistently make the single comparison response that had been cued by the food expectancy, yielding a choice accuracy of about $50 \%$. In fact, S3 and S4 produced different patterns of choice, resulting in an accuracy of approximately $75 \%$ correct in testing.

These findings in no way mean that overt differential behavior explains all differential-outcome effects. Nonetheless, as others (e.g., Peterson, 1984) have noted, it is no coincidence that the central-sounding expectancy closely resembles the fractional anticipatory goal responses and their stimulus properties $\left(r_{\mathrm{g}}-s_{\mathrm{g}}\right)$ proposed by Hull (1931) to explain the directed actions produced by goal attraction.

The point is that the associative account requires that conditioned reactions to the stimuli signaling different outcomes - overt or not - must have detectable stimulus properties in order to function as a discriminative cue. The finding that the signaling stimuli sometimes pro- 
duce overt differential behavior known to have those discriminative properties (Urcuioli \& DeMarse, 1994; Zentall et al., 2001) supports this theoretical position.

\section{S-O and R-O Relations: The Role of Anticipated Versus Consequent Outcomes}

To this point, I have emphasized the role played by $\mathrm{S}-\mathrm{O}$ relations in the differential-outcome effect and in related phenomena, such as transfer of instrumental control from one set of stimuli to another. According to associative two-process theory (Trapold \& Overmier, 1972), these effects reflect the acquisition of stimulus control over instrumental performance by outcome expectancies conditioned via Pavlovian means to the stimuli signaling different outcomes.

Although most findings fit well with this account, some clearly do not. For instance, DeMarse and Urcuioli (1993) reported a differential-outcome effect in symbolic matching despite the fact that the samples alone provided no basis on which to anticipate the scheduled outcomes. Table 8 depicts the main conditions of their study and the expectancy theoretics. Both groups matched each of two samples to two different responses that were available on separate matching trials. For each pair of response alternatives (R1 vs. R2, and R3 vs. R4), one correct response produced one outcome, and the other produced a different outcome in the differential group but each outcome equally often in the nondifferential control. Moreover, the differential $\mathrm{R}-\mathrm{O}$ relations in the former group were arranged so that the outcomes were uncorrelated with the sample stimuli, eliminating the possibility that this group could anticipate the scheduled outcome for a trial just by seeing the sample. Despite this, it acquired the matching task more rapidly than did the nondifferential control.

Studies of the associative structure of instrumental learning (e.g., Colwill \& Rescorla, 1985, 1988; Rescorla, 1992; Rescorla \& Colwill, 1989) have also produced results indicating that consequent outcomes (i.e., the $\mathrm{R}-\mathrm{O}$ relations) may be just as, if not more, fundamental to differential-outcome effects than anticipated outcomes are (i.e., the $\mathrm{S}-\mathrm{O}$ relations). In some of these studies, there were no discrete stimuli to which differential expectancies could be conditioned. Despite this, rats were shown to be sensitive to which outcome reinforced their responses. For example, Colwill and Rescorla (1985) showed that devaluing one outcome following free-operant differentialoutcome training suppressed the responses reinforced by that outcome, but not those reinforced by a different outcome. Similarly, Colwill and Rescorla (1988) showed that free-operant responding reinforced by a particular outcome was preferentially enhanced by a stimulus paired with that same outcome in the absence of responding (see also Blundell et al., 2001, Experiment 2).

The latter results are noteworthy because such transfer effects are typically interpreted as evidence for discriminative control by outcome expectancies (e.g., Overmier \& Linwick, 2001). But this hypothesized source of stimulus control is questionable when reinforced respond- ing occurs in the absence of discrete discriminative stimuli. Rather, it appears that consequent outcomes (i.e., differential $\mathrm{R}-\mathrm{O}$ relations), as opposed to anticipated ones (i.e., differential $\mathrm{S}-\mathrm{O}$ relations), are sufficient to produce these and other effects. The issue then becomes, by what mechanism?

An account that emphasizes the role of $\mathrm{R}-\mathrm{O}$ (consequent outcomes) over $\mathrm{S}-\mathrm{O}$ relations (anticipated outcomes) explains differential-outcome effects in part by assuming that the $\mathrm{R}-\mathrm{O}$ relations are symmetrical or bidirectional (Rescorla, 1992, 1994; cf. Asratyan, 1974; Gormezano \& Tait, 1976). For instance, the bidirectional account states that a stimulus (S) paired with a particular outcome $(\mathrm{O})$ will preferentially enhance responses $(\mathrm{R})$ reinforced with that outcome (e.g., Colwill \& Rescorla, 1988; Peterson, 1984; Urcuioli, 1990a) because (1) such a stimulus elicits a representation of the outcome, and (2) the elicited outcome representation generates the sharedoutcome response via the backward $(\mathrm{O}-\mathrm{R})$ relation. Schematically, $\mathrm{S}-\mathrm{O}$ plus $\mathrm{O}-\mathrm{R}=\mathrm{S}-\mathrm{R}$.

Although the similar terminology (outcome representations vs. expectancies) makes this account and associative two-process theory seem identical, the two have very different requirements for the conditions needed to produce transfer of control. According to two-process theory, transfer requires that instrumental performances during training be explicitly reinforced in the presence of differential-outcome expectancies (i.e., in the context of differential $\mathrm{S}-\mathrm{O}$ relations) because this permits the necessary E-R relations to develop (cf. Table 6). Stated otherwise, if an outcome expectancy cue (E) is not present in training, it cannot develop stimulus control over the very performances that form the basis for transfer. By contrast, the bidirectional account does not require this type of reinforcement history: Differential S-O relations are unnecessary in training; only the $\mathrm{R}-\mathrm{O}$ relations must be differential. Once the latter have been learned, any stimuli generating outcome representations that correspond to the outcomes previously contingent upon responding will enhance those responses.

The latter prediction has been confirmed in studies of pigeons' symbolic matching. Urcuioli and DeMarse

Table 8

Schematic of and Outcome Expectancy Theoretics for the Differential and Nondifferential Outcome Groups in DeMarse and Urcuioli (1993)

\begin{tabular}{|c|c|}
\hline Differential & Nondifferential \\
\hline $\mathrm{S} 1 \rightarrow \mathrm{R} 1(\mathrm{O} 1)$ & $\mathrm{S} 1 \rightarrow \mathrm{R} 1(\mathrm{O} 1 / \mathrm{O} 2)$ \\
\hline $\mathrm{S} 2 \rightarrow \mathrm{R} 2(\mathrm{O} 2)$ & $\mathrm{S} 2 \rightarrow \mathrm{R} 2(\mathrm{O} 1 / \mathrm{O} 2)$ \\
\hline $\mathrm{S} 1 \rightarrow \mathrm{R} 3(\mathrm{O} 2)$ & $\mathrm{S} 1 \rightarrow \mathrm{R} 3(\mathrm{O} 1 / \mathrm{O} 2)$ \\
\hline $\mathrm{S} 2 \rightarrow \mathrm{R} 4(\mathrm{O} 1)$ & $\mathrm{S} 2 \rightarrow \mathrm{R} 4(\mathrm{O} 1 / \mathrm{O} 2)$ \\
\hline \multicolumn{2}{|c|}{ Theoretics } \\
\hline $\mathrm{S} 1-\mathrm{E} 1 / \mathrm{E} 2$ & $\mathrm{~S} 1-\mathrm{E} 1 / \mathrm{E} 2$ \\
\hline $\mathrm{S} 2-\mathrm{E} 1 / \mathrm{E} 2$ & $\mathrm{~S} 2-\mathrm{E} 1 / \mathrm{E} 2$ \\
\hline
\end{tabular}

Note-S1 and S2, sample stimuli; R1-R4, reinforced responses; O1 and $\mathrm{O} 2$, different reinforcing outcomes; $\mathrm{E} 1$ and $\mathrm{E} 2$, expectancies of $\mathrm{O} 1$ and $\mathrm{O} 2$, respectively. 
$(1996,1997)$ showed that differential $\mathrm{R}-\mathrm{O}$ relations in the absence of differential $\mathrm{S}-\mathrm{O}$ relations in training were sufficient to support the subsequent transfer of those responses to other stimuli later paired with the different outcomes (see also Urcuioli, DeMarse, \& Lionello, 1998). In other words, those stimuli preferentially occasioned the comparison responses from training with which they shared a common outcome.

Although findings such as these appear to contradict associative two-process theory, they can, in fact, be accommodated by slight and reasonable theoretical modifications. Examining the training protocols used in the devaluation and transfer studies with rats suggests one such modification. Often, each differentially reinforced response (i.e., each component of the differential $\mathrm{R}-\mathrm{O}$ relation) was trained separately in different sessions. Under these conditions, rats could potentially anticipate the scheduled outcome after receiving the first reinforcer in a session (Jenkins, 1965) or upon seeing which response manipulandum was available. Consequently, those responses could come under stimulus control by different outcome expectancies conditioned to the different manipulanda and/or to different prevailing contextual conditions.

This explanation will not work for all such studies, however. For example, other experiments (e.g., Rescorla, 1992; Rescorla \& Colwill, 1989) were explicitly designed to generate conditions in which subjects would ostensibly anticipate one reinforcer prior to responding but would receive a different reinforcer following responding. In other words, the outcomes participating in the presumably functional $\mathrm{S}-\mathrm{O}$ relations were the opposite of those participating in the juxtaposed $\mathrm{R}-\mathrm{O}$ relations. Thus, it was possible to assess the relative sensitivity of these two sets of relations to posttraining manipulations, such as devaluation and transfer. In all cases, performances appeared to reflect stronger learning about the consequent outcomes ( $\mathrm{R}-\mathrm{O}$ relations) than about the expected outcomes $(\mathrm{S}-\mathrm{O}$ relations).

Here, too, however, two-process theory can be modified in reasonable ways to account for the observed results. Table 9 shows the design of a representative devaluation study, along with two sets of theoretics, one proposing a difference between anticipated and consequent outcomes and the other in which the anticipated and the consequent outcomes match. Phase 2 of training is of particular importance. The proposed theoretics show that the expected outcome preceding each reinforced response differs from the actual consequent outcome: $\mathrm{E} 1$ is present when R1 is reinforced by $\mathrm{O} 2$, and $\mathrm{E} 2$ is present when $\mathrm{R} 2$ is reinforced by $\mathrm{O} 1$. This dissociation supposedly arises from Phase 1 training, during which $\mathrm{S} 1$ signaled $\mathrm{O} 1$ and $\mathrm{S} 2$ signaled $\mathrm{O} 2$. Furthermore, the outcome expectancies initially conditioned to S1 and S2 are thought to persist, at least temporarily, in Phase 2 when the reinforced response (R1) following $\mathrm{S} 1$ now produces $\mathrm{O} 2$ and the reinforced response (R2) following S2 now produces O1.

Granting these assumptions, the bidirectional account predicts that devaluation of one of the outcomes (under- lined) will produce greater suppression of the response that had produced that outcome during Phase 2 (viz., R1) than of the response associated with the expectation of that outcome (viz., R2). By contrast, an unmodified twoprocess account predicts the opposite pattern according to these proposed theoretics: The response (R2) reinforced in the presence of the expectation of the nowdevalued outcome (E2) should be more suppressed. As the bold type under the Testing column indicates, the results showed greater suppression of R1 than of R2, consistent with the view that $\mathrm{R}-\mathrm{O}$ relations are more influential than $\mathrm{S}-\mathrm{O}$ relations.

But a modified two-process theory can also predict this result. The modification assumes that animals learn that the outcomes signaled by the discriminative stimuli vary depending on which response alternative(s) is (are) present. When Rc is available during Phase 1, animals learn that $\mathrm{S} 1$ signals $\mathrm{O} 1$. When $\mathrm{R} 1$ is available during Phase 2, they learn that S1 now signals O2. Similarly, they learn that $\mathrm{S} 2$ signals $\mathrm{O} 2$ when the response option is $\mathrm{Rc}$ and $\mathrm{O} 1$ when the option is R2. By learning these conditional relations, the discriminative stimuli during Phase 2 will generate outcome expectancies that match the actual outcomes for responding, as is shown in the bottom portion of Table 9 .

Of course, the viability of this account hinges on the ability of subjects to vary their outcome expectancies depending on which response alternatives accompany the discriminative stimuli. Pigeons, at least, are capable of doing precisely this. Urcuioli and DeMarse (1996) had them perform two separate, differential-outcome symbolic-matching tasks involving the same two sample stimuli but different comparison (response) alternatives. There were two daily training sessions, one with each set of alternatives. With one set of alternatives, S1 signaled food for correct responding, and S2 signaled the food hopper light only (no food). With the other set of alter-

Table 9

A Devaluation Design (Rescorla, 1992) for Evaluating the Relative Contributions of $\mathrm{R}-\mathrm{O}$ and $\mathrm{S}-\mathrm{O}$ Associations to Differential Outcome Performances and Two Contrasting Theoretics Training

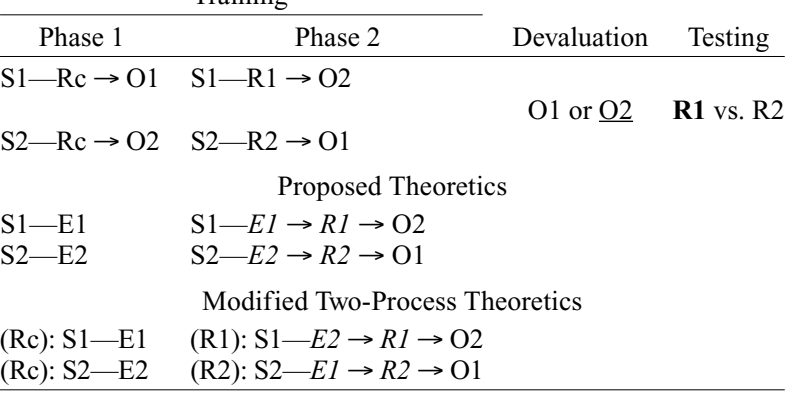

Note-S1 and S2, discriminative stimuli; Rc, R1, and R2, reinforced responses; $\mathrm{O} 1$ and $\mathrm{O} 2$, different reinforcing outcomes; $\mathrm{E} 1$ and $\mathrm{E} 2$, expectancies of $\mathrm{O} 1$ and $\mathrm{O} 2$, respectively. (Rc):, (R1):, and (R2): indicate the presence of different response manipulanda/options. Underlined outcome $=$ devalued. Bolded response $=$ suppressed. 
natives, these $\mathrm{S}-\mathrm{O}$ relations were reversed: $\mathrm{S} 1$ signaled no food, and S2 signaled food. Because pigeons routinely peck signals for food and do not peck signals for no food, their pattern of responding to S1 and S2 indicates whether their outcome expectancies reverse across the alternatives. Figure 6 shows that they did, thus providing independent support for the modified two-process account.

However, this particular modification cannot explain data from tasks in which the response alternatives are not segregated in this fashion (cf. DeMarse \& Urcuioli, 1993). When the trials are intermixed, the response alternatives cannot provide advance information to disambiguate which outcome is scheduled following each observed sample. Despite this, such training is nonetheless sufficient to support transfer of matching (Urcuioli \& DeMarse, 1996, 1997).

Even here, however, the ambiguity regarding the scheduled outcome is removed after the response alternatives appear. In other words, the combination of the comparison alternatives presented during the choice phase of a matching trial along with the sample stimulus that preceded them reliably predicts the outcome scheduled to occur for a correct response. This modified version of two-process theory states that differential-outcome expectancies can arise from serial compounds consisting of each sample stimulus plus the choice alternatives that follow it (DeMarse, 1997; Urcuioli \& DeMarse, 1997; Urcuioli, DeMarse, \& Lionello, 1998; Urcuioli et al., 2001; see also Colwill \& Rescorla, 1990, p. 80). If so, this correctly predicts a differential-outcome effect under conditions in which the sample stimuli by themselves do not signal which outcome is scheduled (DeMarse \& Urcuioli, 1993). Moreover, the reinforced E-R relations

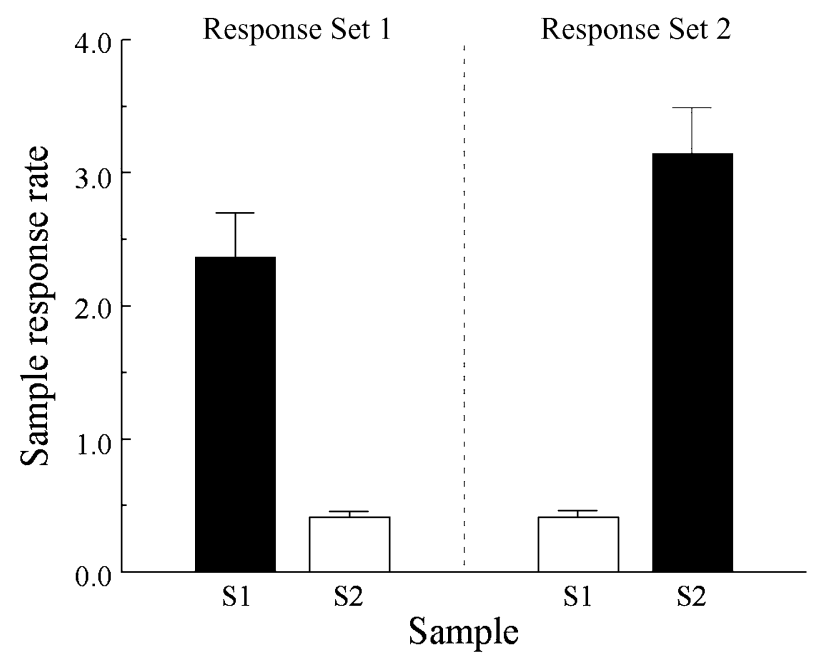

Figure 6. Sample-response rates (pecks/sec) by pigeons to two sample stimuli signaling food versus no-food outcomes for correct comparison responses. Sample-outcome associations for one set of comparison responses were the opposite of those for the other set of comparison responses. Adapted from Urcuioli and DeMarse (1996). that presumably develop under such training conditions should also permit responding to transfer to other stimuli signaling the same outcomes, which also occurs (Urcuioli \& DeMarse, 1996).

The different latencies with which pigeons make the reinforced responses in these types of tasks (DeMarse \& Urcuioli, 1993) provide independent evidence that differential-outcome expectancies can arise from serial compounds. Figure 7 shows that when the samples alone do not predict the contingent outcome but the samples + available alternatives do, pigeons are much slower to respond to comparisons that predictably yield no food than to those that predictably yield food. Apparently, then, pigeons (and presumably other animals) can also discern what combinations of stimuli are reliable signals for upcoming events. That they have evolved such sensitivities and flexibilities to predict the scheduled consequences of their behavior should perhaps be unsurprising. After all, the ability to anticipate those consequences will allow them to adapt quickly and appropriately to changing circumstances in ways that would otherwise be difficult or impossible.

Despite the admittedly subtle theoretical differences described in this section regarding the mechanisms behind the differential-outcome effect, it is important to appreciate the commonality shared by two-process theory, in whatever form it takes, and the bidirectional hypothesis. Specifically, each considers the reinforcer to be an integral part of what is learned in discrimination learning, as opposed to being just a catalyst for learning about other component relations. In one way or another, each account postulates that reinforcers provide another source of stimulus control for behavior.

Interestingly, despite considerable attention devoted to this general point and to the specific issue of the contributions of the $\mathrm{S}-\mathrm{O}$ and $\mathrm{R}-\mathrm{O}$ relations in differential-outcome discriminations (see also Estévez, Overmier, \& Fuentes, 2003; Sherburne \& Zentall, 1998), other studies in the broader literature seem to indicate that reinforcers may also act to catalyze relations that are not directly reinforced during discrimination training but derive from those that are. This will be discussed in the next section.

\section{Differential Outcomes and Equivalence Class Formation}

I have described a number of salient behavioral effects of differential outcomes: facilitation in the rate of discrimination learning, enhanced performances under working memory conditions, and transfer of responding to stimuli with no reinforcement history with regard to such responding. In this section, another potential influence of differential outcomes on discrimination learning will be examined: the joining together of otherwise disparate stimuli into a common class and, possibly, their own inclusion in such classes. To appreciate these effects, it will be necessary to describe how equivalence classes develop and how they are demonstrated. In the course of this discussion, I will address the question of whether the behav- 


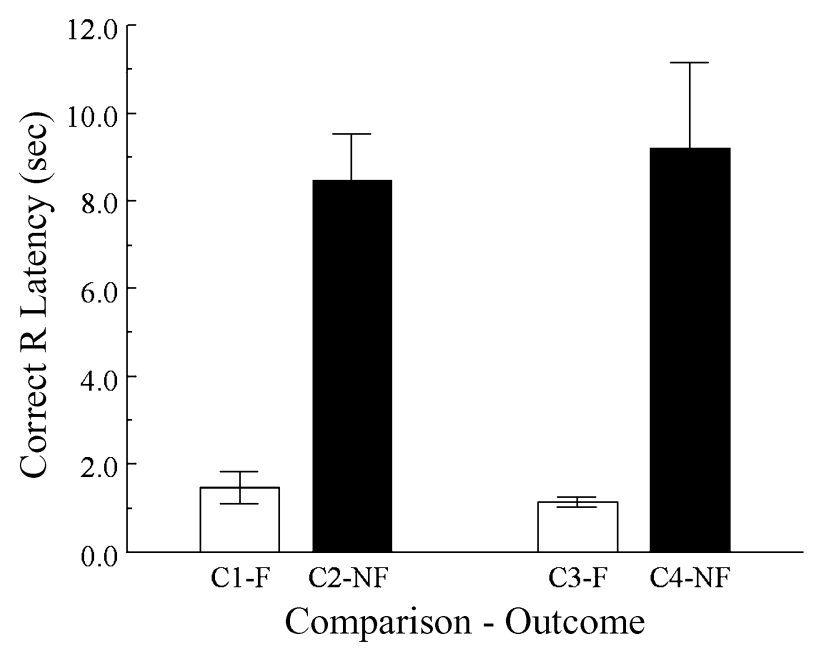

Figure 7. Latency to peck the correct comparisons in symbolic matching with nondifferential sample-outcome relations as a function of whether the comparison choice produced the food (F) or the no-food (NF) outcome. Adapted from DeMarse and Urcuioli (1993).

ioral effects that operationally define class formation arise from the cue properties of outcome expectancies. In other words, I will entertain the possibility that stimulus substitutability, a cardinal feature of all types of equivalence classes (Dougher \& Markham, 1994), reflects stimulus control by differential-outcome expectancies.

Equivalence is demonstrated when stimuli that are explicitly associated with some common event or with one another are shown to be interchangeable in new contexts or in new relations (Honey \& Hall, 1989; Hull, 1939; Sidman, 1994; Spradlin, Cotter, \& Baxley, 1973; Urcuioli, 1996). In other words, the explicitly reinforced S-R relations in discrimination training yield a set of derived, or emergent, $\mathrm{S}-\mathrm{R}$ relations. This means that the discriminative stimuli can now be shown to immediately control other behavior, despite no explicit reinforcement history for doing so, and in ways not explicable by primary stimulus generalization (Zentall, 1998; cf. Honig \& Urcuioli, 1981).

The phenomenon of acquired or functional equivalence (Hall, 1996; Urcuioli, 1996; Wasserman, DeVolder, \& Coppage, 1992) nicely illustrates this. One example involves two or more disparate sample stimuli that occasion the same reinforced comparison choice response in socalled many-to-one matching-to-sample (e.g., Urcuioli \& Lionello-DeNolf, 2001). Although such samples are, by definition, interchangeable with one another because each cues the same comparison response in training, the notion of acquired equivalence implies that this training produces something more than just an overlapping set of learned sample-comparison-response $(\mathrm{S}-\mathrm{R})$ relations (Goldiamond, 1962). In particular, it implies that the samples occasioning the same choice "go together," that they belong to the same class. If so, their interchangeability should transcend the explicitly reinforced training relations. Revealing such an acquired equivalence requires special test procedures. A typical test involves transfer of control: New responses are explicitly conditioned to some stimuli from each presumed class, after which the remaining stimuli are tested to see whether they immediately control those responses. If they do, new S-R relations have clearly emerged, or stated otherwise, the stimuli have been shown to be substitutable for one another outside of original training. This associatively based form of categorization has been routinely observed in humans and many other species (e.g., Bovet \& Vauclair, 1998; Schusterman, Reichmuth, \& Kastak, 2000; Spradlin et al., 1973; Urcuioli \& Lionello-DeNolf, 2001).

Acquired equivalence also develops when stimuli are associated with the same reinforcing outcome. For example, Astley and Wasserman $(1999,2001)$ initially trained pigeons to peck at a large number of photographic slides selected from four different concrete-level categories (people, flowers, cars, and chairs). Pecking at exemplars from two categories (e.g., people and chairs) yielded one reinforcing outcome, whereas pecking at exemplars from the remaining two categories (e.g., flowers and cars) yielded a different reinforcing outcome. The outcomes were different delays to food reinforcement ( 1 vs. $15 \mathrm{sec}$ ), different amounts of food (one vs. five pellets), or different probabilities of food (.1 vs. .9). At issue was whether two perceptually distinct categories of stimuli would combine into a larger superordinate category (an acquired equivalence class) by virtue of their common outcome association. Would pigeons "see" people and chairs as belonging together if each set signaled, say, a large amount of food? Likewise, would flowers and cars become equivalent if each signaled the smaller amount of food?

To evaluate this possibility, Astley and Wasserman $(1999,2001)$ conducted transfer-of-control tests of the general form shown in Table 10. Following differentialoutcome training, pigeons learned new behavior to the stimuli from just two categories, one from each outcome class. Specifically, they learned to choose R1 after seeing stimuli from the $\mathrm{C} 1$ set and $\mathrm{R} 2$ after seeing stimuli from the $\mathrm{C} 3$ set. To avoid "artificially" inducing response preferences, each correct response during the choice training phase was reinforced equally often by each outcome. However, the original associations between the four stimulus sets and the two outcomes were maintained by intermixing blocks of differential-outcome trials with blocks of choice trials (not shown). After pigeons learned to accurately match R1 and R2 to $\mathrm{C} 1$ and $\mathrm{C} 3$, respectively, they were tested to see whether they would preferentially choose R1 after C2 and R2 after C4, despite no reinforcement history of doing so. Such preference would suggest the formation of two acquired equivalence classes - $[\mathrm{C} 1, \mathrm{C} 2]$ and $[\mathrm{C} 3, \mathrm{C} 4]$ - arising from shared outcome associations. In fact, across experiments, the pigeons preferred to make the class-consistent responses on $75 \%-87 \%$ of the test trials, well above the level expected by chance. 
The acquired equivalence characterization of these findings implies that differential outcomes had catalyzed the development of stimulus-stimulus relations: $\mathrm{C} 1$ and $\mathrm{C} 2$ were now in the same equivalence class, and likewise C3 and C4. But as Astley and Wasserman $(1999,2001)$ noted, the observed preferences can be readily explained by associative two-process theory. Differential-outcome expectancies established during initial training and maintained during choice training had likely acquired stimulus control over R1 and R2. Consequently, the E1 and E2 expectancies in testing continued to cue $\mathrm{R} 1$ versus $\mathrm{R} 2$ when $\mathrm{C} 2$ and $\mathrm{C} 4$ now appeared prior to these choice alternatives. Thus, $\mathrm{C} 2$ was substitutable for $\mathrm{C} 1$ (and $\mathrm{C} 4$ for C3) because (1) each generated the same outcome expectancy and (2) that expectancy had been established as a discriminative cue for a particular choice response.

This characterization of the results is identical to that used for results obtained from typical transfer-of-control tests of the cue properties of outcome expectancies, a point that can be appreciated by comparing Table 10 with Table 6. Thus, what appears to be an acquired equivalence between stimuli signaling a common outcome may not necessarily reflect the emergence of untrained relations, meaning derivative control over responding by the nominal stimuli themselves. Rather, the results may simply reflect the continuing influence of the explicitly trained $\mathrm{E}-\mathrm{R}$ relations (cf. Urcuioli, 1996).

Stimulus control by the class members themselvesemergent relations, in the true sense of that phrasewhich would be consistent with a catalytic effect of reinforcement, requires evidence that performances during a successful transfer test are not cued by outcome expectancies. To accomplish this, it is necessary to create an equivalence test in which either the stimuli appearing in testing do not elicit differential-outcome expectancies or the responses required in testing have not previously come under stimulus control of such expectancies. This is a tall order.

Table 10

Tests of Acquired Equivalence Based on Shared Outcome Associations (From Astley and Wasserman, 1999, 2001)

\begin{tabular}{ccc}
\hline $\begin{array}{c}\text { Differential Outcome } \\
\text { Training }\end{array}$ & $\begin{array}{c}\text { Choice } \\
\text { Training }\end{array}$ & Transfer Test \\
\hline $\mathrm{C} 1 \rightarrow \mathrm{O} 1$ & & \\
$\mathrm{C} 2 \rightarrow \mathrm{O} 1$ & $\mathrm{C} 1 \rightarrow \mathrm{R} 1(\mathrm{O} 1 / \mathrm{O} 2)$ & $\mathrm{C} 2 \rightarrow \underline{\mathrm{R} 1}$ vs. R2 \\
$\mathrm{C} 3 \rightarrow \mathrm{O} 2$ & $\mathrm{C} 3 \rightarrow \mathrm{R} 2(\mathrm{O} 1 / \mathrm{O} 2)$ & $\mathrm{C} 4 \rightarrow \mathrm{R} 1$ vs. $\underline{\mathrm{R} 2}$ \\
$\mathrm{C} 4 \rightarrow \mathrm{O} 2$ & &
\end{tabular}

Theoretics

$\begin{array}{lll}\mathrm{C} 1-\mathrm{E} 1 & & \\ \mathrm{C} 2-\mathrm{E} 1 & \mathrm{C} 1-\mathrm{E} 1 \rightarrow \mathrm{R} 1 & \mathrm{C} 2-\mathrm{E} 1 \rightarrow \mathrm{R} 1 \\ \mathrm{C} 3-\mathrm{E} 2 & \mathrm{C} 3-\mathrm{E} 2 \rightarrow \mathrm{R} 2 & \mathrm{C} 4-\mathrm{E} 2 \rightarrow \mathrm{R} 2\end{array}$

Note-C1-C4, sets of perceptually similar stimuli (categories); R1 and $\mathrm{R} 2$, reinforced responses; $\mathrm{O} 1$ and $\mathrm{O} 2$, outcomes; $\mathrm{E} 1$ and $\mathrm{E} 2$, expectancies of $\mathrm{O} 1$ and $\mathrm{O} 2$, respectively. Underlining indicates the preferred response, assuming acquired equivalence between stimulus sets associated with the same outcome during differential-outcome training.
One approach is to see whether the outcomes themselves will cue the responses that had originally produced them. This test is based on the supposition that differential-outcome training produces classes containing not only the stimuli associated with those outcomes, but also the outcomes as well (Sidman, 1994). Astley and Wasserman (2001, Experiment 3) conducted such a test but found that pigeons matched at chance levels of accuracy, a result inconsistent with the formation of an outcome-based equivalence class. Dickinson and de Wit (2003) obtained similar, negative findings in rats. Urcuioli and DeMarse (1997, Experiment 2), however, found that pigeons did accurately match outcomes to the responses that had produced them following training in which the samples alone were uncorrelated with the outcomes. Researchers studying equivalence in humans have found that they, too, are often able to match the outcomes as samples to the comparison responses that produced those outcomes during training (Dube \& Mcllvane, 1995; Dube, McIlvane, Mackay, \& Stoddard, 1987; Joseph, Overmier, \& Thompson, 1997; Schenk, 1994). The reasons for the discrepancies are not clear. However, in at least one study with humans (Dube et al., 1987), the positive test results appear to reflect the two-process mechanism: The outcomes had also served as samples in some training relations, creating the possibility that expectancies conditioned to those outcome samples developed stimulus control over the responses measured in testing.

Demonstrations of stimulus equivalence in humans typically use different training and testing protocols than do those for acquired equivalence (cf. Sidman, 1994). Subjects are often trained on two sets of conditional relations, during which they learn to match $\mathrm{B}$ comparisons to A samples (A-B matching) and C comparisons to B samples (B-C matching). Following such training, humans often exhibit the ability to match those stimuli to one another in novel ways. For instance, they will readily match A comparisons to B samples and B comparisons to $\mathrm{C}$ samples (symmetry), as well as $\mathrm{C}$ to $\mathrm{A}$ (transitivity) and $\mathrm{A}$ to $\mathrm{C}$ (combined symmetry and transitivity). These emergent performances show that even in the absence of differential outcomes, conditional discrimination training has led to the formation of equivalence classes involving the $\mathrm{A}, \mathrm{B}$, and $\mathrm{C}$ stimuli.

Adding differential outcomes to the training relations is of interest for several reasons. First, differential outcomes may facilitate stimulus class formation, and second, it may produce classes that also contain the reinforcing outcomes themselves (Sidman, 1994, 2000). Consistent with these ideas is the finding that emergent relations such as symmetry are generally more likely to appear and/or are performed more accurately following conditional discrimination training with differential outcomes than following training with nondifferential outcomes (Joseph et al., 1997). Similarly, emergent relations have been shown to develop to stimuli that have no direct matching relation to one another, provided that they share a common out- 
come association (Dube et al., 1987; Dube, McIlvane, Maguire, Mackay, \& Stoddard, 1989; Schenk, 1994). For example, following differential-outcome training on two separate identity matching tasks, $\mathrm{A}-\mathrm{A}$ and $\mathrm{B}-\mathrm{B}$, many subjects will immediately match $\mathrm{B}$ comparisons to $\mathrm{A}$ samples and vice versa (viz., A-B and B-A matching; Dube \& McIlvane, 1995; Schenk, 1994).

The latter results are noteworthy because pigeons, too, show accurate $\mathrm{A}-\mathrm{B}$ and $\mathrm{B}-\mathrm{A}$ matching following comparable types of identity training (Edwards et al., 1982). The explanation for the pigeon data, however, appeals to stimulus control over the B and A responses by the differential-outcome expectancies that develop during identity training. Interestingly, in nearly every differentialoutcome stimulus equivalence study with humans that obtained positive test results, those data can also be explained in this fashion (see also de Rose et al., 1988). No appeal to emergent relations between the nominal samples and comparisons is necessary, because once again, subjects can learn during training to (1) anticipate which outcome is scheduled following a variety of samples and (2) use their differential-outcome expectancies as a cue for selecting the reinforced comparison response. In short, the continued presence of these reinforced training relations during testing captures how subjects behave on the equivalence test trials.

Analogous differential-outcome experiments with animals that otherwise do not exhibit the range of emergent relations commonly seen with humans also reveal test performances suggestive of stimulus equivalence (Kastak, Schusterman, \& Kastak, 2001; Meehan, 1999). But here, too, the data follow at once from the principles embodied in associative two-process theory. In sum, the ability of humans and other animals to match stimuli associated with the same, differential outcome to one another does not, for the most part, require anything more than an appeal to discriminative control by outcome expectancies established during training.

There are, however, a few notable exceptions, and these may well be an indication that differential outcomes can potentially enhance the relations among stimuli, including themselves. Successful outcome-sample transfer tests following conditional discrimination training in which the outcomes were not used as sample stimuli are a case in point. The only way in which such transfer data can be accommodated by associative two-process theory is to assume stimulus generalization between each outcome and its expectancy. For example, if the actual presentation of food is more similar to the expectancy of food than, say, to the expectancy of water, and vice versa for the actual presentation of water, the E-R relations reinforced during training should preferentially generalize to the corresponding $\mathrm{O}-\mathrm{R}$ relations in testing. Whether or not such an assumption is reasonable remains to be seen.

Another result that points rather strongly to the possible catalytic effect of reinforcement comes from the literature on rats' spatial memory (Macuda \& Roberts,
1995). Rats were trained on a 12 -arm radial maze in which the three different foods were placed at the ends of different arms. Four arms/spatial locations always contained one food, another four a second food, and the remaining four the third. The rats were observed in training to visit similar-outcome locations together in a serial fashion. More important, when the foods at the ends of the arms were later interchanged, the rats made fewer errors (viz., returning to a previously visited and now foodabsent arm) when the sets of locations in training continued to maintain a common outcome association in testing, despite the change in the outcome at those locations. In other words, when the original location groupings, defined in terms of common outcome associations, were maintained in testing, it was easier to complete the maze run than when the location groupings were changed. Macuda and Roberts claimed that original differentialoutcome training had caused rats to chunk, or to group together, the common-outcome locations. Continued coherence of those groups following the outcome switch led to less disruption than did group reorganization. Given the uncertainty about whether outcome expectancy mediation could produce such a finding, it seems reasonable to attribute the effects of different food outcomes to the development of location-location (equivalence class) relations.

\section{Summary and Conclusions}

I have attempted to provide a reasonably comprehensive review of the empirical and theoretical literature on the differential-outcome effect. Those familiar with this literature will undoubtedly notice gaps and omissions in the coverage, but my selectivity has been in the service of trying to underscore what I see as the main contribution of this paradigm to the understanding of instrumental learning processes. The reinforcers that are crucial to the behavioral changes that define instrumental/operant conditioning do not simply play a supporting role for learning about what to do under what circumstances but, instead, are also part of what is learned. Anticipation of different response-contingent reinforcers can clearly serve a discriminative function. Indeed, anticipating the availability versus unavailability of a single reinforcer can be easily shown to exert a similar function (Urcuioli, DeMarse, \& Zentall, 1998; Urcuioli \& Zentall, 1990, 1992). In short, outcome expectancies can be part of the circumstances that direct action.

Associative two-process theory, as originally outlined by Trapold (1970), is notable not only for its ability to encompass such a wide range of differential-outcome results, but also for the simplicity and familiarity of the mechanisms it proposes. Accustomed as we are to thinking of discrimination in terms of stimulus control by events external to us, this theory essentially says that such control can also arise from stimuli that are internal and that its development follows the usual stimulus control "rules." Responses differentially reinforced in the presence of certain stimuli-be they external or inter- 
nal -will come under control of those stimuli. The idea of internal stimuli that behave in a manner similar to exteroceptive ones is embraced elsewhere in psychological science (e.g., Davidson, 1998), so it should hardly be controversial here.

Admittedly, there are some findings not easily amenable to a two-process account, in either its original or its modified forms. These findings suggest that there may be other mechanisms by which reinforcers influence instrumental performance. In some cases (e.g., Colwill \& Rescorla, 1990, Experiment 1), however, those mechanisms nonetheless require that the reinforcer itself become part of the learning matrix, albeit in more complex ways than those discussed here. In other situations (e.g., Macuda \& Roberts, 1995; see also Joseph et al., 1997), the reinforcer may help to engender learning about other relations, a function that harkens back to some of the older views of what reinforcers do. Given that theoretical history, it would be a bit ironic if future research definitively establishes a catalytic function as well. Then again, showing that the instrumental reinforcer can have multiple functions should, perhaps, not be a surprise (cf. Corbit \& Balleine, 2003).

All told, however, the answer to Trapold's (1970) question- "Are expectancies based upon different positive reinforcing events discriminably different?"-is clearly yes.

\section{REFERENCES}

Alling, K., Nickel, M., \& Poling, A. (1991a). The effects of differential and nondifferential outcomes on response rates and accuracy under a delayed-matching-to-sample procedure. Psychological Record, 41, 537-549.

Alling, K., Nickel, M., \& Poling, A. (1991b). The effects of phenobarbital on responding under delayed-matching-to-sample procedures with differential and nondifferential outcomes. Pharmacology, Biochemistry, \& Behavior, 39, 817-820.

ASRATYAN, E. A. (1974). Conditioned reflex theory and motivational behavior. Acta Neurobiologiae Experimentalis, 34, 15-31.

AstLey, S. L., \& WaSSERMAN, E. A. (1999). Superordinate category formation in pigeons: Association with a common delay or probability of food reinforcement makes perceptually dissimilar stimuli functionally equivalent. Journal of Experimental Psychology: Animal Behavior Processes, 25, 413-432.

Astley, S. L., \& Wasserman, E. A. (2001). Superordinate categorization via learned stimulus equivalence: Quantity of reinforcement, hedonic value, and the nature of the mediator. Journal of Experimental Psychology: Animal Behavior Processes, 27, 252-268.

BLUNDELl, P., HALL, G., \& KILlCROSS, S. (2001). Lesions of the basolateral amygdala disrupt selective aspects of reinforcer representation in rats. Journal of Neuroscience, 21, 9018-9026.

Bovet, D., \& VAUCLAIR, J. (1998). Functional categorization of objects and of their pictures in baboons (Papio anubis). Learning \& Motivation, 29, 309-322.

BrodigAN, D. L., \& Peterson, G. B. (1976). Two-choice conditional discrimination performance of pigeons as a function of reward expectancy, prechoice delay, and domesticity. Animal Learning \& Behavior, 4, 121-124.

CARLSON, J. G., \& WIELKIEWICZ, R. M. (1972). Delay of reinforcement in instrumental discrimination learning of rats. Journal of Comparative \& Physiological Psychology, 81, 365-370.

CaRLSON, J. G., \& WiELKIEWICZ, R. M. (1976). Mediators of the effects of magnitude of reinforcement. Learning \& Motivation, 7, 184-196.
Chatlosh, D. L., \& Wasserman, E. A. (1992). Memory and expectancy in delayed discrimination procedures. In I. Gormezano \& E. A. Wasserman (Eds.), Learning and memory: The behavioral and biological substrates (pp. 61-79). Hillsdale, NJ: Erlbaum.

ColwILl, R. M. (1994). Associative representations of instrumental contingencies. In D. L. Medin (Ed.), The psychology of learning and motivation (Vol. 31, pp. 1-72). New York: Academic Press.

Colwill, R. M., \& Rescorla, R. A. (1985). Post-conditioning devaluation of a reinforcer affects instrumental responding. Journal of Experimental Psychology: Animal Behavior Processes, 11, 120-132.

COLWILl, R. M., \& Rescorla, R. A. (1986). Associative structures in instrumental learning. In G. H. Bower (Ed.), The psychology of learning and motivation (Vol. 20, pp. 55-104). New York: Academic Press.

Colwill, R. M., \& Rescorla, R. A. (1988). Associations between the discriminative stimulus and the reinforcer in instrumental learning. Journal of Experimental Psychology: Animal Behavior Processes, 14, 155-164.

CoLWILl, R. M., \& ResCorla, R. A. (1990). Evidence for the hierarchical structure of instrumental learning. Animal Learning \& Behavior, 18, 71-82.

CoRbit, L. H., \& Balleine, B. W. (2003). Instrumental and Pavlovian incentive processes have dissociable effects on components of a heterogeneous instrumental chain. Journal of Experimental Psychology: Animal Behavior Processes, 29, 99-106.

DAVIDSON, T. L. (1998). Hunger cues as modulatory stimuli. In N. A. Schmajuk \& P. C. Holland (Eds.), Occasion setting: Associative learning and cognition in animals (pp. 223-248). Washington, DC: American Psychological Association.

DeLong, R. E., \& WaSserman, E. A. (1981). Effects of differential reinforcement expectancies on successive matching-to-sample performance in pigeons. Journal of Experimental Psychology: Animal Behavior Processes, 7,394-412.

DEMARSE, T. B. (1997). Differential expectancies produced by stimuli followed by nondifferential outcomes: A serial-compound view. Unpublished doctoral dissertation, Purdue University.

DeMarse, T. B., \& UrCuioli, P. J. (1993). Enhancement of matching acquisition by differential comparison-outcome associations. Journal of Experimental Psychology: Animal Behavior Processes, 19, 317-326.

de Rose, J. C., McIlvane, W. J., Dube, W. V., Galpin, V. C., \& StodDARD, L. T. (1988). Emergent sample discrimination established by indirect relation to differential consequences. Journal of the Experimental Analysis of Behavior, 50, 1-20.

DiCKINSON, A., \& DE WIT, S. (2003). The interaction between discriminative stimuli and outcomes during instrumental learning. Quarterly Journal of Experimental Psychology, 56B, 127-139.

DONAHOE, J. W., \& BURGOS, J. E. (2000). Behavior analysis and revaluation. Journal of the Experimental Analysis of Behavior, 74, 331-346.

Dougher, M. J., \& MARKhaM, M. R. (1994). Stimulus equivalence, functional equivalence, and the transfer of function. In S. C. Hayes, L. J. Hayes, M. Sato, \& K. Ono (Eds.), Behavior analysis of language and cognition (pp. 71-90). Reno, NV: Context Press.

Dube, W. V., \& MCIlvane, W. J. (1995). Stimulus-reinforcer relations and emergent matching to sample. Psychological Record, $\mathbf{4 5}, 591-$ 612.

Dube, W. V., McIlvane, W. J., Mackay, H. A., \& Stoddard, L. T. (1987). Stimulus class membership established by stimulus-reinforcer relations. Journal of the Experimental Analysis of Behavior, 47, 159-175.

Dube, W. V., McIlvane, W. J., MaguiRe, R. W., MackaY, H. A., \& STODDARD, L. T. (1989). Stimulus class formation and stimulus-reinforcer relations. Journal of the Experimental Analysis of Behavior, 51, 65-76.

Edwards, C. A., Jagielo, J. A., Zentall, T. R., \& HoG (1982). Acquired equivalence and distinctiveness in matching to sample by pigeons: Mediation by reinforcer-specific expectancies. Journal of Experimental Psychology: Animal Behavior Processes, $\mathbf{8}_{2}$ 244-259.

Estévez, A. F., Fuentes, L. J., Overmier, J. B., \& González, C. (2003). Differential outcomes effect in children and adults with Down syndrome. American Journal of Mental Retardation, 108, 108-116. Estévez, A. F., Overmier, B., \& Fuentes, L. J. (2003). Differential 
outcomes effect in children: Demonstration and mechanisms. Learning \& Motivation, 34, 148-167.

FedorchaK, P. M., \& BolLes, R. C. (1986). Differential outcome effect using a biologically neutral outcome difference. Journal of Experimental Psychology: Animal Behavior Processes, 12, 125-130.

FrIEDMAN, G. J., \& CARLSON, J. G. (1973). Effects of a stimulus correlated with positive reinforcement upon discrimination learning. Journal of Experimental Psychology, 97, 281-286.

Friedrich, A. M., \& Zentall, T. R. (2004, May). A differential outcomes effect using two different feeder locations. Paper presented at the 76th Annual Meeting of the Midwestern Psychological Association, Chicago.

Goldiamond, I. (1962). Perception. In A. J. Bachrach (Ed.), Experimental foundations of clinical psychology (pp. 280-340). New York: Basic Books.

GoODWIN, A. K., \& BAKER, L. E. (2002). An analysis of the utility of differential outcome procedures in drug discrimination research. Behavioural Pharmacology, 13, 271-278.

Gormezano, I., \& TAIT, R. W. (1976). The Pavlovian analysis of instrumental conditioning. Pavlovian Journal of Biological Science, 11, 37-55.

GUTHRIE, E. R. (1935). The psychology of learning. New York: Harper.

HALL, G. (1996). Learning about associatively activated stimulus representations: Implications for acquired equivalence and perceptual learning. Animal Learning \& Behavior, 24, 233-255.

HochHalter, A. K., \& JosePH, B. (2001). Differential outcomes training facilitates memory in people with Korsakoff and Prader-Willi syndromes. Integrative Physiological \& Behavioral Science, 36, 196-204.

Hochhalter, A. K., Sweeney, W. A., BaKke, B. L., Holub, R. J., \& OVERMier, J. B. (2000). Improving face recognition in alcohol dementia. Clinical Gerontologist, 22, 3-18.

Honey, R. C., \& Hall, G. (1989). The acquired equivalence and distinctiveness of cues. Journal of Experimental Psychology: Animal Behavior Processes, 15, 338-346.

HoNIG, W. K., \& DodD, P. W. D. (1986). Anticipation and intention in working memory. In D. F. Kendrick, M. E. Rilling, \& M. R. Denny (Eds.), Theories of animal memory (pp. 77-100). Hillsdale, NJ: Erlbaum.

Honig, W. K., Matheson, W. R., \& Dodd, P. W. D. (1984). Outcome expectancies as mediators for discriminative responding. Canadian Journal of Psychology, 38, 196-217.

Honig, W. K., \& Urcuioli, P. J. (1981). The legacy of Guttman and Kalish (1956): Twenty-five years of research on stimulus generalization. Journal of the Experimental Analysis of Behavior, 36, 405-445.

Hull, C. L. (1930). Knowledge and purpose as habit mechanisms. Psychological Review, 37, 511-525.

Hull, C. L. (1931). Goal attraction and directing ideas conceived as habit phenomena. Psychological Review, 38, 487-506.

Hull, C. L. (1939). The problem of stimulus equivalence in behavior theory. Psychological Review, 46, 9-30.

Hull, C. L. (1943). Principles of behavior. New York: AppletonCentury-Crofts.

Hull, C. L. (1952). A behavior system. New Haven, CT: Yale University Press.

JENKINS, H. M. (1965). The measurement of stimulus control during discriminative operant conditioning. Psychological Review, 38, 487-506.

Jenkins, H. M., \& Moore, B. R. (1973). The form of the auto-shaped response with food and water reinforcers. Journal of the Experimental Analysis of Behavior, 20, 163-181.

JoNes, B. M., \& White, K. G. (1994). An investigation of the effect of differential-outcomes effect within sessions. Journal of the Experimental Analysis of Behavior, 61, 389-406.

JoNES, B. M., White, K. G., \& ALSOP, B. L. (1995). On two effects of signaling the consequences for remembering. Animal Learning \& Behavior, 23, 256-272.

JOSEPH, B., OvERMIER, J. B., \& THOMPSON, T. (1997). Food- and nonfoodrelated differential outcomes in equivalence learning by adults with Prader-Willi syndrome. American Journal on Mental Retardation, 101, 374-386.

KASTAK, C. R., Schusterman, R. J., \& Kastak, D. (2001). Equivalence classification by California sea lions using class-specific reinforcers. Journal of the Experimental Analysis of Behavior, 76, 131-158.

KELLY, R., \& GRANT, D. S. (2001). A differential outcomes effect using biologically neutral outcomes in delayed matching-to-sample with pigeons. Quarterly Journal of Experimental Psychology, 54B, 69-79.

Kruse, J. M., Overmier, J. B., KonZ, W. A., \& RoKke, E. (1983). Pavlovian conditioned stimulus effects on instrumental choice behavior are reinforcer specific. Learning \& Motivation, 14, 165-181.

LitT, M. D., \& Schreibman, L. (1981). Stimulus-specific reinforcement in the acquisition of receptive labels by autistic children. Analysis \& Intervention in Developmental Disabilities, 1, 171-186.

Mackintosh, N. J. (1977). Stimulus control: Attentional factors. In W. K. Honig \& J. E. R. Staddon (Eds.), Handbook of operant behavior (pp. 481-513). New York: Appleton-Century-Crofts.

Macuda, T., \& RoberTs, W. A. (1995). Further evidence for hierarchical chunking in rat spatial memory. Journal of Experimental Psychology: Animal Behavior Processes, 21, 20-32.

MaKi, P., Overmier, J. B., Delos, S., \& GutManN, A. J. (1995). Expectancies as factors influencing conditional discrimination performance of children. Psychological Record, $\mathbf{4 5}, 45-71$.

Malanga, P., \& Poling, A. (1992). Letter recognition by adults with mental handicaps: Improving performance through differential outcomes. Developmental Disabilities Bulletin, 20, 39-48.

Meehan, E. F. (1999). Class-consistent differential reinforcement and stimulus class formation in pigeons. Journal of the Experimental Analysis of Behavior, 72, 97-115.

MiLES, C. G., \& JENKINS, H. M. (1973). Overshadowing in operant conditioning as a function of discriminability. Learning \& Motivation, $\mathbf{4}$, 11-27.

Miller, O., Waugh, K. M., \& Chambers, K. (2002). Differential outcomes effect: Increased accuracy in adults learning Kanji with stimulusspecific rewards. Psychological Record, 52, 315-324.

MiYashita, Y., NaKaJima, S., \& Imada, H. (2000). Differential outcome effect in the horse. Journal of the Experimental Analysis of Behavior, 74, 245-253.

Morgan, T. B., \& BAKER, L. E. (1997). The application of differential outcomes to a cocaine-saline discrimination procedure. Behavioural Pharmacology, 8, 31-36.

NAKAJIMA, S., \& KoBAYASHI, H. (2000). Differential outcomes effect on instrumental serial feature-ambiguous discrimination in rats. Psychological Record, 50, 189-198.

OVERMier, J. B., Bul L, J. A., III, \& Trapold, M. A. (1971). Discriminative cue properties of different fears and their role in response selection in dogs. Journal of Comparative \& Physiological Psychology, 76. 478-482.

OVERMIER, J. B., \& LAWRY, J. A. (1979). Pavlovian conditioning and the mediation of behavior. In G. H. Bower (Ed.), The psychology of learning and motivation (Vol. 13, pp. 1-55). Hillsdale, NJ: Erlbaum.

Overmier, J. B., \& Linwick, D. (2001). Conditional choice-unique outcomes establish expectancies that mediate choice behavior. Integrative Physiological \& Behavioral Science, 36, 173-181.

Overmier, J. B., SAVAGE, L. M., \& SweEneY, W. A. (1999). Behavioral and pharmacological analyses of memory: New behavioral options for remediation. In M. Haug \& R. E. Whalen (Eds.), Animal models of human emotion and cognition (pp. 231-245). Washington, DC: American Psychological Association.

PaPini, M. R., \& Silingardi, C. A. (1989). Mechanisms of acquisition of behavioral sequences in rats. Learning \& Motivation, 20, 73-86.

Peterson, G. B. (1984). How expectancies guide behavior. In H. L. Roitblat, T. G. Bever, \& H. S. Terrace (Eds.), Animal cognition (pp. 135-148). Hillsdale, NJ: Erlbaum.

Peterson, G. B., Linwick, D., \& Overmier, J. B. (1987). On the comparative efficacy of memories and expectancies as cues for choice behavior in pigeons. Learning \& Motivation, 18, 1-20.

Peterson, G. B., \& Trapold, M. A. (1980). Effects of altering outcome expectancies on pigeons' delayed conditional discrimination performance. Learning \& Motivation, 11, 267-288.

Peterson, G. B., \& Trapold, M. A. (1982). Expectancy mediation of concurrent conditional discriminations. American Journal of Psychology, 95, 371-380. 
Peterson, G. B., Wheeler, R. L., \& Armstrong, G. D. (1978). Expectancies as mediators in the differential-reward conditional discrimination performance of pigeons. Animal Learning \& Behavior, 6, 279-285

Peterson, G. B., Wheeler, R. L., \& Trapold, M. A. (1980). Enhancement of pigeons' conditional discrimination performances by expectancies of reinforcement and nonreinforcement. Animal Learning \& Behavior, 8, 22-30.

Ramos, R., \& SAVAGE, L. M. (2003). The differential outcomes procedure can interfere or enhance operant rule learning. Integrative Physiological \& Behavioral Science, 38, 17-35.

RESCORLA, R. A. (1992). Response-outcome and outcome-response associations in instrumental learning. Animal Learning \& Behavior, 20, 223-232.

ResCORLA, R. A. (1994). Transfer of instrumental control mediated by a devalued outcome. Animal Learning \& Behavior, 22, 27-33.

Rescorla, R. A., \& Colwill, R. M. (1989). Associations with anticipated and obtained outcomes in instrumental learning. Animal Learning \& Behavior, 17, 291-303.

RESCORLA, R. A., \& SolOMON, R. L. (1967). Two-process learning theory: Relationships between Pavlovian conditioning and instrumental learning. Psychological Review, 74, 151-182.

SAnti, A., \& Roberts, W. A. (1985a). Prospective representation: The effects of varied mapping of sample stimuli to comparison stimuli and differential trial outcomes on pigeons' working memory. Animal Learning \& Behavior, 13, 103-108.

SANTI, A., \& RoberTs, W. A. (1985b). Reinforcement expectancy and trial spacing effects in delayed matching-to-sample by pigeons. Animal Learning \& Behavior, 13, 274-284.

SAUNDERS, R. R., \& SAILOR, W. (1979). A comparison of three strategies of reinforcement on two-choice learning problems with severely retarded children. AAESPH Review, 4, 323-333.

SAVAGE, L. M. (2001). In search of the neurobiological underpinnings of the differential outcomes effect. Integrative Physiological \& Behavioral Science, 36, 182-195.

SAVAGE, L. M., \& PARSONS, J. (1997). The effects of delay interval, intertrial interval, amnestic drugs, and differential outcomes on matching-to-position in rats. Psychobiology, 25, 303-312.

Savage, L. M., Pitkin, S. R., \& Careri, J. M. (1999). Memory enhancement in aged rats: The differential outcomes effect. Developmental Psychobiology, 35, 318-327.

Savage, L. M., PitKin, S. R., \& KNITOwski, K. M. (1999). Rats exposed to acute pyrithiamine-induced thiamine deficiency are more sensitive to the amnestic effects of scopolamine and MK-801: Examination of working memory, response selection, and reinforcement contingencies. Behavioural Brain Research, 104, 13-26.

SCHENK, J. J. (1994). Emergent relations of equivalence generated by outcome-specific consequences in conditional discrimination. Psychological Record, 44, 537-558.

Schusterman, R. J., Reichmuth, C. J., \& Kastak, D. (2000). How animals classify friends and foes. Current Directions in Psychological Science, 9, 1-6.

SHEPP, B. E. (1962). Some cue properties of anticipated rewards in discrimination learning of retardates. Journal of Comparative \& Physiological Psychology, 55, 856-859.

SHEPP, B. E. (1964). Some cue properties of rewards in simultaneous object-discriminations of retardates. Child Development, 35, 587592.

Sherburne, L. M., \& Zentall, T. R. (1995). Pigeons transfer between conditional discriminations with differential outcomes in the absence of differential-sample-responding cues. Animal Learning \& Behavior, 23, 273-279.

Sherburne, L. M., \& Zentall, T. R. (1998). The differential outcomes effect in pigeons is not reduced by eliminating response-outcome associations: Support for a two-process account. Animal Learning \& Behavior, 26, 378-387.

SiDMAN, M. (1994). Equivalence relations and behavior: A research story. Boston: Authors Cooperative.

SIDMAN, M. (2000). Equivalence relations and the reinforcement contingency. Journal of the Experimental Analysis of Behavior, 74, 127-146.
SkINNER, B. F. (1953). Science and human behavior. New York: Macmillan.

SPENCE, K. (1956). Behavior theory and conditioning. New Haven, CT: Yale University Press.

Spradlin, J. E., Cotter, V. W., \& Baxley, N. (1973). Establishing conditional discrimination without direct training: A study of transfer with retarded adolescents. American Journal of Mental Deficiency, 77, 556-566.

TERRACE, H. S. (1966). Stimulus control. In W. K. Honig (Ed.), Operant behavior: Areas of research and application (pp. 271-344). New York: Appleton-Century-Crofts.

Thorndike, E. L. (1911). Animal intelligence: Experimental studies. New York: Macmillan.

Tolman, E. C. (1932). Purposive behavior in animals and men. New York: Century.

Tolman, E. C. (1933). Sign-Gestalt or conditioned reflex? Psychological Review, 40, 246-255.

TraPOLD, M. A. (1970). Are expectancies based upon different positive reinforcing events discriminably different? Learning \& Motivation, 1, 129-140.

TrAPOLD, M. A., \& Overmier, J. B. (1972). The second learning process in instrumental learning. In A. H. Black \& W. F. Prokasy (Eds.), Classical conditioning II: Current research and theory (pp. $427-$ 452). New York: Appleton-Century-Crofts.

UrCUIOLI, P. J. (1984). Overshadowing in matching-to-sample: Reduction in sample-stimulus control by differential sample behaviors. Animal Learning \& Behavior, 12, 256-264.

URCUIOLI, P. J. (1990a). Differential outcomes and many-to-one matching: Effects of correlation with correct choice. Animal Learning \& Behavior, 18, 410-422.

UrCuioli, P. J. (1990b). Some relationships between outcome expectancies and sample stimuli in pigeons' delayed matching. Animal Learning \& Behavior, 18, 302-314.

URCUIOLI, P. J. (1991). Retardation and facilitation of matching acquisition by differential outcomes. Animal Learning \& Behavior, 19, 29-36.

Urcuioli, P. J. (1996). Acquired equivalences and mediated generalization in pigeon's matching-to-sample. In T. R. Zentall \& P. M. Smeets (Eds.), Stimulus class formation in humans and animals (pp. 55-70). Amsterdam: Elsevier.

UrCuioli, P. J., \& DeMarse, T. B. (1994). On the relationship between differential outcomes and differential sample responding in matchingto-sample. Journal of Experimental Psychology: Animal Behavior Processes, 20, 249-263.

URCUIOLI, P. J., \& DeMARSE, T. B. (1996). Associative processes in differential outcome discriminations. Journal of Experimental Psychology: Animal Behavior Processes, 22, 192-204.

UrCuioli, P. J., \& DeMarse, T. B. (1997). Further tests of responseoutcome associations in differential-outcome matching-to-sample. Journal of Experimental Psychology: Animal Behavior Processes, 23, 171-182.

URCUIOLI, P. J., DeMarse, T. B., \& Lionello, K. M. (1998). Transfer of performance to new comparison choices following differential outcome matching-to-sample. Animal Learning \& Behavior, 26, 139-153. Urcuioli, P. J., DeMarse, T. B., \& Lionello-DeNolf, K. M. (2001). Assessing the contributions of $\mathrm{S}-\mathrm{O}$ and $\mathrm{R}-\mathrm{O}$ associations to differentialoutcome matching through outcome reversals. Journal of Experimental Psychology: Animal Behavior Processes, 27, 239-251.

UrCuioli, P. J., DeMarse, T. B., \& Zentall, T. R. (1998). Transfer across delayed discriminations: II. Differences in the substitutability of initial versus test stimuli. Journal of Experimental Psychology: Animal Behavior Processes, 24, 47-59.

UrCUIOLI, P. J., \& Honig, W. K. (1980). Control of choice in conditional discriminations by sample-specific behaviors. Journal of Experimental Psychology: Animal Behavior Processes, 6, 251-277.

UrCuioli, P. J., \& Lionello-DeNolf, K. M. (2001). Some tests of the anticipatory mediated generalization model of acquired sample equivalence in pigeons' many-to-one matching. Animal Learning \& Behavior, 29, 265-280.

URCUIOLI, P. J., \& ZENTALL, T. R. (1990). On the role of trial outcomes in delayed discriminations. Animal Learning \& Behavior, 18, 141-150. 
Urcuioli, P. J., \& Zentall, T. R. (1992). Transfer across delayed discriminations: Evidence regarding the nature of prospective working memory. Journal of Experimental Psychology: Animal Behavior Processes, 18, 154-173.

Wagner, A. R., Logan, F. A., Haberlandt, K., \& Price, T. (1968). Stimulus selection in animal discrimination learning. Journal of Experimental Psychology, 76, 171-180.

Wasserman, E. A., DeVolder, C. L., \& Coppage, D. J. (1992). Nonsimilarity-based conceptualization in pigeons. Psychological Science, 3, 374-379.

Williams, D. A., Butler, M. M., \& Overmier, J. B. (1990). Expectancies of reinforcer location and quality as cues for a conditional discrimination in pigeons. Journal of Experimental Psychology: Animal Behavior Processes, 16, 3-13.
Zentall, T. R. (1998). Symbolic representation in animals: Emergent stimulus relations in conditional discrimination learning. Animal Learning \& Behavior, 26, 363-377.

Zentall, T. R., Clement, T. S., Bhatt, R. S., \& Allen, J. (2001) Episodic-like memory in pigeons. Psychonomic Bulletin \& Review, 8, 685-690.

ZENTALl, T. R., \& Sherburne, L. M. (1994). Role of differential sample responding in the differential outcomes effects involving delayed matching by pigeons. Journal of Experimental Psychology: Animal Behavior Processes, 20,390-401.

(Manuscript received June 11, 2004; accepted for publication July 26, 2004.) 